\title{
Estratigrafía y paleontología del Cenozoico marino del Gran Bajo y Salinas del Gualicho, Argentina, y descripción de 17 especies nuevas
}

\author{
Valeria A. Reichler \\ Departamento de Ciencias Geológicas, Facultad de Ciencias Exactas y Naturales, Universidad de Buenos Aires. Ciudad Universi- \\ taria, Pabellón II, $1^{\circ}$ Piso (1428) Buenos Aires, Argentina. \\ valereichler@bbt11.com.ar
}

RESUMEN. La estratigrafía de la Formación Gran Bajo del Gualicho se presenta con mayor detalle, proponiéndose los nuevos Miembros Saladar y Arriola, precisando la sucesión faunística integrada por 35 géneros y 41 especies, de las cuales 17 son nuevas y se describen en este estudio: Anadara australis sp. nov., Cubitostrea delrioi sp. nov., Amusium rorii sp. nov., Zygochlamys rizzoloi sp. nov., Pododesmus (Monia) atlantica sp. nov., Tawera canalei sp. nov., Dosinia (Dosinia) salarensis sp. nov., 'Spirocolpus' adapicis sp. nov., Torcula magna sp. nov., Magnatica hansi sp. nov., Eudolium lissiei sp. nov., Sconsia magdai sp. nov., Chicoreus (Chicoreus) guadalupei sp. nov., Penion patagonensis sp. nov., Mitra (Fusimitra) carlosi sp. nov., Austroimbricaria brugnii sp. nov. y Polystira cingula sp. nov. El reconocimiento de la Asociación de Moluscos NVG (Nodipecten sp.-Venericor abasolensis-Glycymerita camaronesia) sitúa al Miembro Saladar nov. en el Mioceno Temprano alto-Mioceno Medio bajo y lo correlaciona con la sección superior de la Formación Chenque y con los estratos portadores de Venericor de las formaciones Gaiman y Vaca Mahuida. La fauna de este miembro constituye una evidencia más respecto a la diferenciación en franjas climáticas postulada para Patagonia a partir del Oligoceno Tardío-Mioceno Temprano. En el Miembro Arriola nov., la asociación recuperada indica probablemente la biozona de Aequipecten paranensis y su relación estratigráfica con la Formación Puerto Madryn del Mioceno Tardío bajo, extendiendo el área abarcada por la Provincia Valdesiana hasta las Salinas del Gualicho. La fauna del Miembro Saladar presenta mayor afinidad con las que integran las formaciones Monte León y Chenque, mientras que la del Miembro Arriola es más afín con las de las formaciones Puerto Madryn y Paraná. Las formaciones chilenas Navidad y Guadal presentan respectivamente el 30\% y el 10\% de los géneros en común con la fauna del Miembro Saladar.

Palabras clave: Moluscos, Cenozoico, Formación Gran Bajo del Gualicho, Nuevas especies, Patagonia, Argentina.

\begin{abstract}
Stratigraphy and Paleontology of the marine Cenozoic from the Gran Bajo and Salinas del Gualicho, Argentina and description of $\mathbf{1 7}$ new species. The stratigraphy of the Gran Bajo del Gualicho Formation is explained by the identification of the new Saladar and Arriola Members. The molluscan fauna comprises 38 genera and 44 species, 17 of which are new: Anadara australis sp. nov., Cubitostrea delrioi sp. nov., Amusium rorii sp. nov., Zygochlamys rizzoloi sp. nov., Pododesmus (Monia) atlantica sp. nov., Tawera canalei sp. nov., Dosinia (Dosinia) salarensis sp. nov., 'Spirocolpus' adapicis sp. nov., Torcula magna sp. nov., Magnatica hansi sp. nov., Eudolium lissiei sp. nov., Sconsia magdai sp. nov., Chicoreus (Chicoreus) guadalupei sp. nov., Penion patagonensis sp. nov., Mitra (Fusimitra) carlosi sp. nov., Austroimbricaria brugnii sp. nov. y Polystira cingula sp. nov. The NVG (Nodipecten sp.-Venericor abasolensis- Glycymerita camaronesia) Molluscan Assemblage in the Saladar Member nov. indicates an age of late Early Miocene-earliest Middle Miocene. The Saladar Member correlates with the upper section of the Chenque Formation and with the Venericor bearing horizons of the Gaiman and Vaca Mahuida formations. The fauna of this member constitutes another evidence with respect to the weather stripes stated for Patagonia since the Late Oligocene-Early Miocene. The assemblage recorded in the Arriola Member nov. indicates the probable presence of the Aequipecten parenensis Zone and a stratigraphic relationship with the Puerto Madryn Formation of a Late Miocene age, extending the covered area along the Valdesian Province to the Salinas del Gualicho. The fauna of the Saladar Member shows more affinity with that in the Monte León and Chenque formations, while the fauna in the Arriola Member shares more resemblance with the Paraná and Puerto Madryn formations. The Chilean Navidad and Guadal formations have 30\% and $10 \%$ of genus in common with fauna of the Saladar Member, respectively.
\end{abstract}




\section{Introducción}

El estudio de la secuencia sedimentaria marina cenozoica aflorante en el área del Gran Bajo y Salinas del Gualicho (Fig. texto 1) permite proponer para la Formación Gran Bajo del Gualicho (Lizuain y Sepúlveda, 1978) los nuevos miembros Saladar y Arriola, acotados temporalmente en virtud de la fauna asociada. Se presenta la composición y afinidades de los moluscos determinados y se comparan las asociaciones con las de otras formaciones marinas cenozoicas de la Patagonia argentina y chilena, efectuándose inferencias paleoclimáticas e implicancias biogeográficas. Se describen e ilustran las especies nuevas (Apéndice Paleontología).

El material fósil (bien preservado: conchillas originales o moldes litificados, yesificados o silicificados) está contenido en las sedimentitas localizadas en la margen sur de la cuenca del Colorado, al NE del Macizo Norpatagónico ( $40^{\circ} 00^{\prime} \mathrm{S}-40^{\circ} 30^{\prime} \mathrm{S}$; $64^{\circ} 45^{\prime} \mathrm{O}-$ $66^{\circ} 15^{\circ} \mathrm{O}$ ), región centro-oriental de la Provincia de Río Negro, en la Patagonia argentina. El sector occidental del área estudiada se ubica entre el Gran Bajo del Gualicho por el norte y la Bolsa del Gualicho al sur, mientras que el oriental se sitúa entre las barrancas del Gualicho al norte y el Puesto Urceda al sur (Fig. texto 1). Hasta el momento el ciclo depositacional de la Formación Gran Bajo del Gualicho no ha sido claro y sus fósiles solo fueron estudiados parcialmente (Figueiras, 1985; Aguirre- Urreta, 1990; Scarabino et al., 2004; Martínez et al., 2005; Del Río y Martínez, 2006; Del Río, 2007). El estudio sistemático de los fósiles hallados y las observaciones estratigráficas efectuadas en el presente trabajo arrojan alguna luz sobre estos problemas, al diferenciar los nuevos miembros (Fig. texto 2). Las investigaciones más antiguas fueron efectuadas por Wichmann ${ }^{1} \mathrm{y}$ Wichmann $(1916,1919,1927)$, estableciendo para la zona pautas geológico-estratigráficas. Kaaschieter (1965) refirió una posible correlación entre las sedimentitas aflorantes en la zona de la costa de Río Negro y aquellas dispuestas en la región de los bajos, mientras que Rizzolo (1967) realizó un relevamiento estratigráfico del área reconociendo las unidades aflorantes y Núñez et al. (1975) mencionaron para la zona afloramientos de la 'Formación Patagonia' que correlacionaron con Cona Niyeu por el oeste y Cerro El Fuerte por el este. Lizuain y Sepúlveda (1978) describieron las formaciones geológicas aflorantes en el área del Gran Bajo del Gualicho, definiendo las formaciones Arroyo Barbudo y Gran Bajo del Gualicho. Riggi (1981) ${ }^{2}$ efectuó un estudio estratigráfico-sedimentológico de las sedimentitas aflorantes en el área del portezuelo Puerta del Diablo,

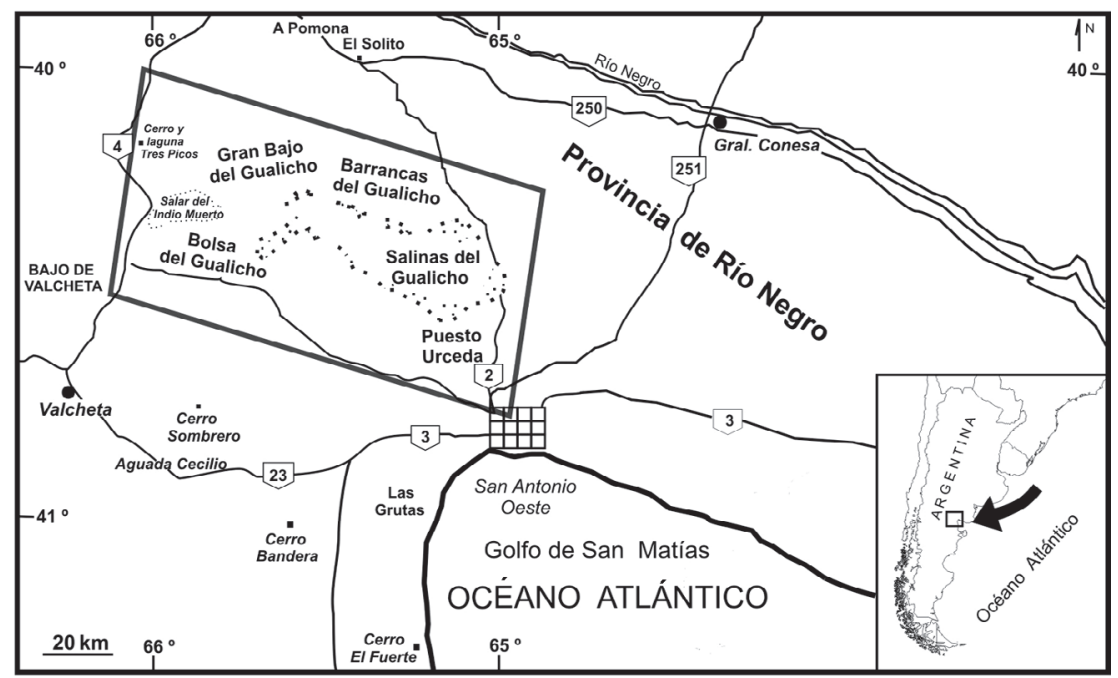

Fig. texto 1. Ubicación geográfica del área estudiada.

Wichmann, R. 1927. Observaciones geológicas en la parte central y oriental de Río Negro. Servicio Geológico Nacional (Informe Inédito): 1-16.

Riggi, J.C. 1981. Litología de la Formación Puerta del Diablo, correspondiente a la Hoja 38i, Bajo del Gualicho. Servicio Geológico Nacional (Informe Inédito): 1-8. 


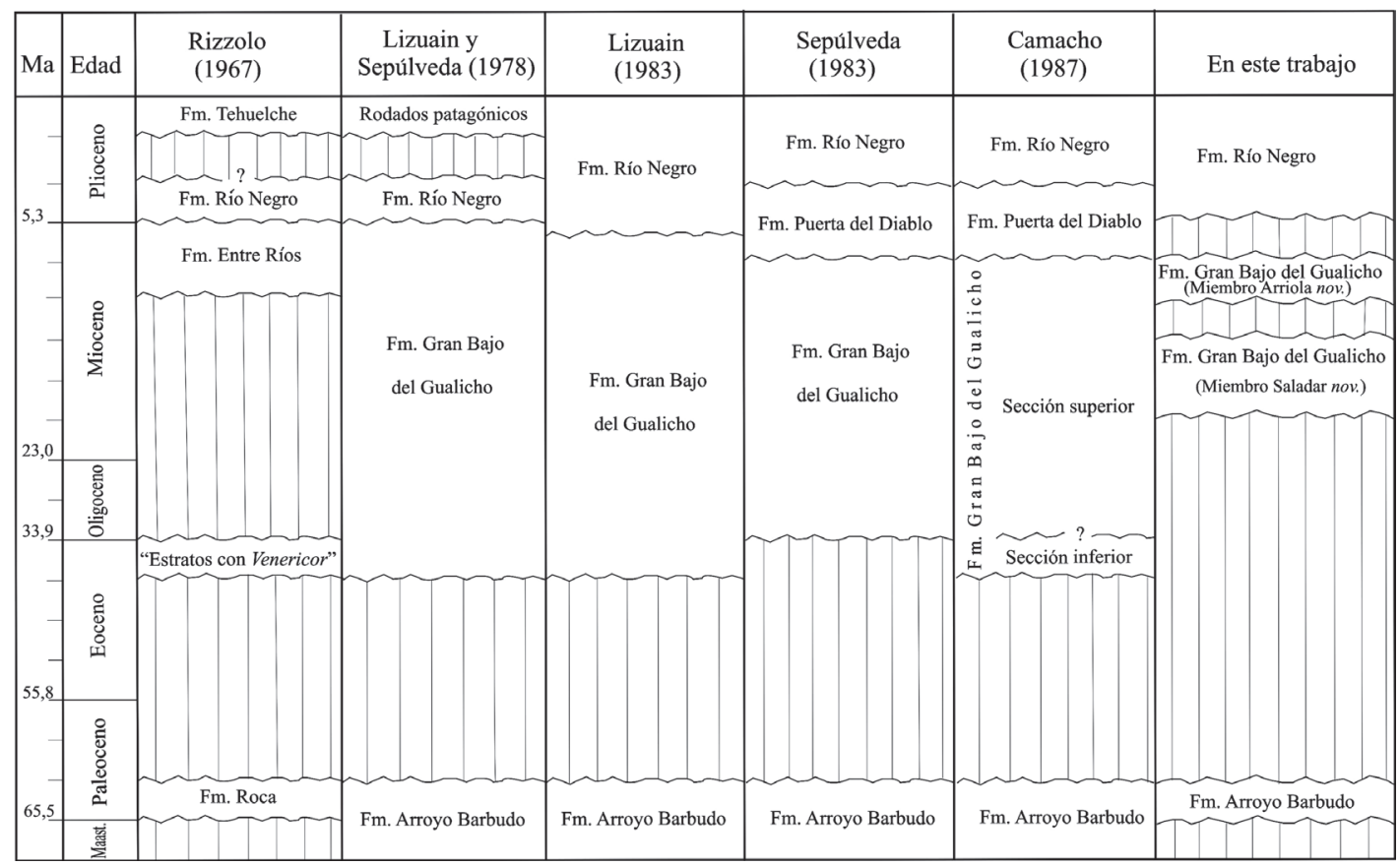

Fig. texto 2. Esquema comparativo entre la estratigrafía adoptada por autores precedentes y el esquema estratigráfico propuesto en este estudio.

sector oriental de la Bolsa del Gualicho. En 1983 se publicaron las hojas geológicas 38i, 'Gran Bajo del Gualicho' (Sepúlveda, 1983) y 38j, 'Salinas del Gualicho' (Lizuain, 1983). Las mismas se han tomado como base para la presente investigación. Posteriormente, Franchi et al. (1984) correlacionaron la secuencia mio-pliocena del Gran Bajo del Gualicho con la parte cuspidal de la Formación Barranca Final de la perforación Pedro Luro sobre la costa atlántica. Por otra parte, Camacho (1987) efectuó un estudio bioestratigráfico de los depósitos cenozoicos aflorantes en la parte norte del Bajo, en el que destaca la presencia de una interesante fauna de moluscos, estableciendo su relación respecto a la Formación Gran Bajo del Gualicho. Finalmente, Angelucci et al. (1996) efectuaron consideraciones geológicas del área, mientras que Sepúlveda (2003) esbozó una síntesis de la geología de las mesetas y bajos de la zona, principalmente en el ámbito del Gran Bajo del Gualicho.

\section{Marco general estratigráfico de la zona}

Las sedimentitas paleógenas más antiguas registradas en el área corresponden al Daniano y están incluidas en la Formación Arroyo Barbudo (Lizuain y Sepúlveda, 1978) (Fig. texto 3, perfiles E-F) que aflora frente a la Estancia El Puma y en las márgenes del arroyo Barbudo, inmediaciones del Salar del Indio Muerto y Cerro Tres Picos. En esta formación se han identificado los dos miembros: el Inferior, de areniscas yesíferas, areniscas arcillosas y pelitas arenosas y el Superior de areniscas líticas de grano grueso con yeso y coquinas rojas con elevada bioturbación. La megafauna es escasa, la presencia de Pycnodonte (Phygraea) burckhardti (Böhm) y Hercoglossa rionegrensis Reichler en el Miembro Inferior corroboran su edad daniana (Reichler, 1989; Reichler y Camacho, 1991; Reichler, 1995) y lo correlacionan con la Formación El Fuerte (Kaasschieter, 1963).

En forma pseudoconcordante sobre las areniscas precedentes se dispone la Formación Gran Bajo del Gualicho (Lizuain y Sepúlveda, 1978) (Fig. texto 3, perfiles A-F; H) que conforma el cuerpo principal de las barrancas que rodean las Salinas del Gualicho distribuyéndose aisladamente en el área del Gran Bajo (alrededores del arroyo Barbudo, Puerta del Diablo y Bolsa del Gualicho). Afloramientos aledaños a la Ruta Provincial No. 2, que une San Antonio Oeste 

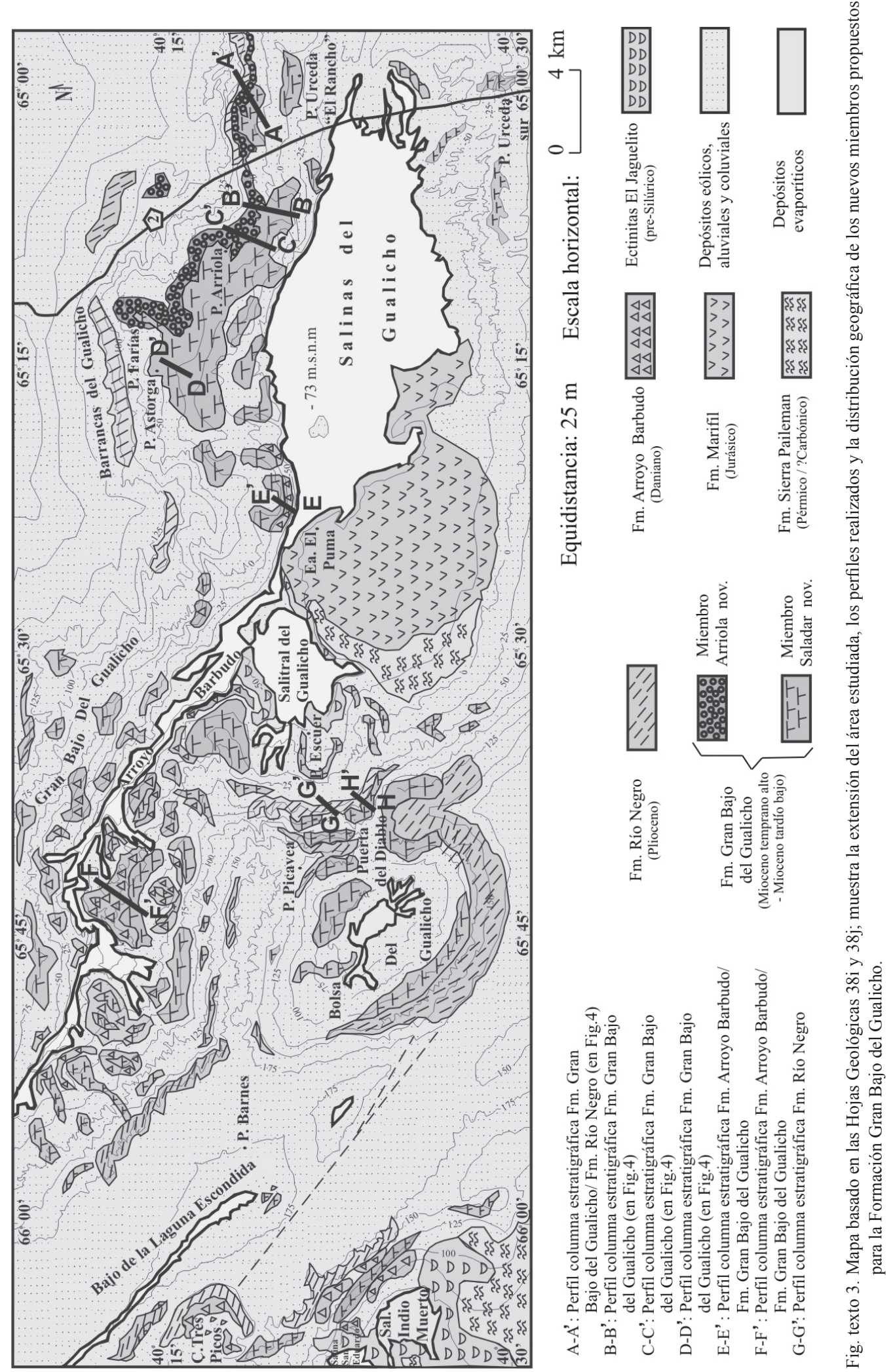
con Pomona, se asignan también a esta formación. Solo en las inmediaciones del arroyo Barbudo se ha observado el contacto subyacente, siempre con la Formación Arroyo Barbudo, a través de una pseudoconcordancia. Luego de una discordancia erosiva, los afloramientos de la Formación Gran Bajo del Gualicho están cubiertos por las areniscas de la Formación Río Negro tanto en el área de las Salinas como en el Gran Bajo. Se ha reconocido la localidad tipo, ampliando significativamente su paleontología, correlacionando los diferentes sectores de la formación a lo largo de todo el Gran Bajo y Salinas del Gualicho (Fig. texto 4). En el presente estudio se propone, dentro de la Formación Gran Bajo del Gualicho, la denominación formal de los miembros Saladar nov. y Arriola nov. (según requisitos del CAE, 1992: Art.31-b), claramente distinguibles litológica y paleontológicamente, separados por una paraconcordancia.

La Formación Río Negro (Andreis, 1965; Plioceno), caracterizada por areniscas continentales gris-azuladas, se dispone luego de una discordancia erosiva sobre las formaciones Arroyo Barbudo (sector del Salar del Indio Muerto y Cerro Tres Picos) y Gran Bajo del Gualicho, conformando la sección superior de las elevaciones aledañas a la ruta provincial No. 2, al oriente de las Salinas del Gualicho y las inmediaciones de Puerta del Diablo, Puesto Escuer y Bolsa del Gualicho en el Gran Bajo del Gualicho (Fig. texto 3, perfiles A, G y H). El ciclo sedimentario concluye con un manto de Rodados Patagónicos.

\section{Formación Gran Bajo del Gualicho (Lizuain y Sepúlveda, 1978)}

\subsection{Miembro Saladar nov.} Areniscas bioclásticas, coquinas, pelitas, yeso

\subsubsection{Localidad tipo, distribución areal y relacio- nes estratigráficas}

Se propone este nombre para identificar las sedimentitas de origen marino pertenecientes a la Formación Gran Bajo del Gualicho comprendidas entre el techo de la Formación Arroyo Barbudo y la base del Miembro Arriola nov. Se designa como localidad tipo al área de las Salinas del Gualicho constituida por los niveles inferiores y medios de las barrancas que marginan la Gran Salina, hasta la cota de 51 m s.n.m. (Fig. texto 3, perfil tipo: C: $\left.40^{\circ} 19^{\prime} \mathrm{S} ; 65^{\circ} 08^{\prime} \mathrm{O}\right)$. Este miembro también se halla representado en el Puesto Astorga (40 $15^{\prime} \mathrm{S} ; 6^{\circ}$ $\left.15^{\prime} \mathrm{O}\right)$ e inmediaciones de la ruta No. $2\left(40^{\circ} 18^{\prime} \mathrm{S}\right.$; $65^{\circ} 04^{\prime} \mathrm{O}$ ). Afloramientos correspondientes a los estratos inferiores se han identificado en el área del Gran Bajo del Gualicho, en la Puerta del Diablo-Bolsa del

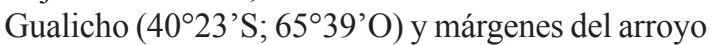

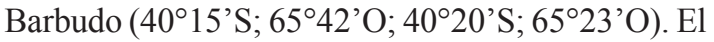
espesor varía entre 2 y $36,50 \mathrm{~m}$. El contacto con la Formación Arroyo Barbudo es pseudoconcordante y solo se ha identificado en el área del Gran Bajo, inmediaciones del arroyo Barbudo (Fig. texto 3, perfil F) y en el extremo occidental de la Gran Salina, frente a Estancia El Puma (Fig. texto 3, perfil E). En las Salinas del Gualicho, el Miembro Saladar nov. es cubierto a su vez por el Miembro Arriola nov. del cual se separa a través de una paraconcordancia (Fig. texto 3, perfiles A, B, C y D), mientras que en la zona del Gran Bajo del Gualicho una discordancia erosiva lo separa de la Formación Río Negro suprayacente (Fig. texto 3, perfil H).

\subsubsection{Litología y ambiente de los depósitos}

Se distingue por el predominio de areniscas bioclásticas, coquinas, pelitas, yeso y por la recurrencia vertical de pequeñas discontinuidades estratigráficas evidenciadas por niveles encostrados (estratos de muy poco espesor, fuertemente cementados, con aspecto de 'costra' y fauna silicificada subordinada) con elevada bioturbación. Las estructuras sedimentarias son escasas, generalmente estratificación planar gruesa o laminación.

La secuencia está caracterizada por estratos horizontales o subhorizontales, con un leve hundimiento en dirección al SO, principalmente al occidente de la Gran Salina. En su parte inferior, los afloramientos están compuestos por areniscas limo-arcillosas blanco-grisáceas que alternan con coquinas, diques yesíferos y areniscas bioclásticas ricas en bivalvos y gastrópodos. Hacia la parte media de los afloramientos se incrementa el tamaño de grano y la coloración se caracteriza por diversos tonos de ocre y amarillo. Los estratos están separados por superficies onduladas; los más friables contienen pequeños bivalvos fragmentados y balánidos, mientras que los más compactos son portadores de grandes bivalvos y gastrópodos. Aquí aparecen por primera vez niveles encostrados (espesor: 10 a $15 \mathrm{~cm}$ ), muy bioturbados, portadores de fauna silicificada que se vuelven recurrentes hacia la parte superior del miembro. Los estratos superiores son 
los más potentes e involucran una alternancia de areniscas, pelitas y coquinas gruesas, separadas por superficies erosivas. La coloración varía entre gris muy claro, ocre y pardo. Hacia los últimos términos, se acentúa la presencia de areniscas bioclásticas ocres muy friables de grano grueso con numerosos equinodermos. Esta sucesión litológica estaría indicando un ambiente depositacional transgresivo de aguas someras con una evolución de facies desde depósitos de plataforma hasta típicos depósitos de playa. La evolución no sería continua ya que, a pesar de la falta de registros estratigráficos detallados, las discontinuidades estratigráficas evidenciadas por los niveles encostrados indicarían la presencia de 'hardgrounds', sugiriendo diferentes estadios de variaciones rápidas del nivel del mar, debidos a movimientos eustáticos.

La sucesión finaliza en todos los casos con un banco subtabular de arenisca bioclástica de grano grueso ocre oscuro muy consolidada, acuñado lateralmente (espesor entre 0,70 y 1,40 m), con base y techo ondulados y elevada concentración de Arenicolites y Thalassinoides que constituye el límite con el miembro suprayacente. Dicho límite se interpreta como una paraconcordancia cuyo contacto inclina moderadamente hacia el este, con una pendiente aproximada de $2^{\circ}$, probablemente vinculada a la original de la cuenca. El criterio utilizado para su reconocimiento es la existencia de una superficie de omisión (paraconformidad sedimentológica) que marca una interrupción en la sedimentación evidenciada por una intensa bioturbación asociada a cavidades menores de disolución y a un proceso de endurecimiento del sustrato que se reconoce por la presencia de organismos litófagos (Pholadidea aff. patagonica Philippi y Pholadidea sp.) en los estratos basales del miembro suprayacente. La presencia de Arenicolites y Thalassinoides asociados al tope de la unidad estarían indicando la existencia de la icnofacies de Glossifungites que en ambientes marinos someros se presenta comúnmente asociada a superficies formadas por retroceso erosivo del ‘shoreface' (Buatois y Mángano, 2000).

\subsubsection{Contenido fosilifero}

En este miembro los fósiles son numerosos y diversificados, siendo sus principales componentes bivalvos, gastrópodos y equinodermos (fauna transportada). En los estratos basales de la sección inferior los gastrópodos identificados son los siguien- tes: Valdesia (Juliania) aff. seudocollaris Morra y Del Río, 'Spirocolpus' adapicis sp. nov., Torcula magna sp. nov., Perissodonta ameghinoi (Ihering), Siphocypraea posei (Figueiras), Magnatica hansi sp. nov., Eudolium lissiei sp. nov., Ficus distans (Sowerby), Sconsia magdai sp. nov., Chicoreus (Chicoreus) guadalupei sp. nov., Penion patagonensis sp. nov., Mitra (Fusimitra) carlosi sp. nov., Austroimbricaria brugnii sp. nov., Adelomelon posei Scarabino, Martínez, Del Río, Oleinik, Camacho y Zinsmeister, Pachycymbiola camachoi del Río y Martínez, Pachycymbiola arriolensis del Río y Martínez, Conus aff. infulatus Hoerle y Polystira cingula sp. nov. Entre los bivalvos destaca Venericor (Neovenericor) austroplata Gardner y Bowles, junto a Iheringinucula sp., Anadara australis sp. nov., Glycymerita cuevensis (Ihering), Glycymerita camaronesia (Ihering), Amusium rorii sp. nov., Nodipecten salis del Río, Lucinidae sp., Purpurocardia sp., 'Hedecardium' sp. 1, 'Hedecardium' sp. 2, Tawera canalei sp. nov., Dosinia (Dosinia) salarensis sp. nov., Panopea aff. nucleus (Ihering) y Panopea cf. quemadensis Ihering. También se han hallado Dentalium sp., fragmentos de equinodermos y dientes de seláceos. En la sección media aparecen por primera vez los equinodermos Abertella gualichensis Martínez, Reichler y Mooi y Monophoraster darwini (Desor). En todos los casos Monophoraster aparece estratigráficamente antes que Abertella y posteriormente ambos coexisten en una misma asociación. El resto de la fauna se halla integrando los niveles encostrados con la asociación Venericor (Neovenericor) austroplata, Glycymerita camaronesia, Glycymerita cuevensis, Perissodonta ameghinoi, Magnatica hansi sp. nov., Abertella gualichensis y/o Monophoraster darwini. Hacia la sección superior los bivalvos y gastrópodos disminuyen en cantidad y diversidad mientras aumenta considerablemente la cantidad de equinodermos (Abertella gualichensis y Monophoraster darwini), dominando hacia el techo del miembro Abertella. Las areniscas bioclásticas friables de los niveles más altos son portadoras de Amusium rorii sp. nov., Nodipecten salis, Lucinidae indet., Tawera canalei sp. nov., Dosinia (Dosinia) salarensis sp. nov., Panopea aff. nucleus, Panopea cf. quemadensis, 'Spirocolpus' adapicis sp. nov. y Adelomelon posei. En el último estrato se han hallado Abertella gualichensis y Monophoraster darwini asociados a Venericor (Neovenericor) austroplata y Amusium rorii sp. nov. 


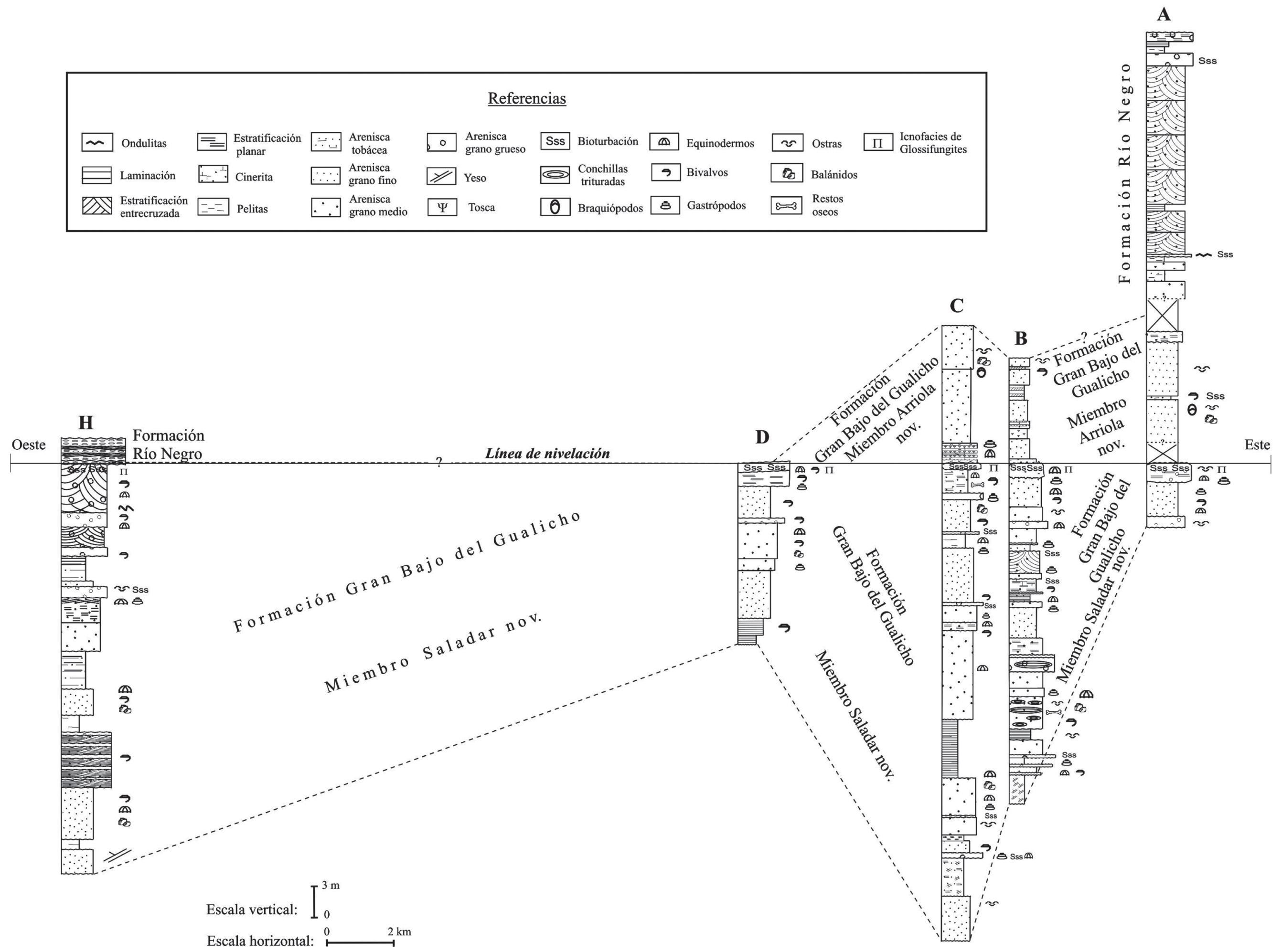

Fig. texto 4. Correlación de perfiles de la Formación Gran Bajo del Gualicho (línea de nivelación: superficie de contacto entre los Miembros Saladar nov. y Arriola nov.). 


\subsubsection{Edad y correlaciones}

Rizzolo $(1967,1968)$ correlacionó las sedimentitas del Miembro Saladar nov. con las identificadas a lo largo de la costa patagónica hasta el golfo de San Jorge, posteriormente denominadas 'Estratos con Monophoraster y Venericor' (Camacho, 1974, 1995). Al presente, en el área de la cuenca de San Jorge, estos estratos están incluidos en la Formación Chenque (Bellosi, 1990; Barreda y Palamarczuk, 2000a, b; Barreda, 2002), definida para agrupar los sedimentos de la región que bordean dicho golfo y representan el relleno del 'mar superpatagoniano' en esa cuenca. Reichler (1989) y Reichler y Camacho (1991) realizaron un estudio bioestratigráfico del Terciario marino entre los cerros Fuerte Argentino y Bandera, estableciendo la relación entre los estratos eo-oligocenos costeros y sus equivalentes en la zona del Gran Bajo del Gualicho, confirmando la presencia de la sección inferior de la Formación Gran Bajo del Gualicho, en discordancia erosiva sobre la Formación El Fuerte (Daniano) y subyacente a la Formación Río Negro. Se indicó una posible correlación entre la Formación Gran Bajo del Gualicho aflorante en el área del Cerro Fuerte Argentino y la Formación Vaca Mahuida (Uliana, 1973). Posteriormente, Busteros et al. (1998) incluyeron las sedimentitas aflorantes en el área de los cerros Fuerte Argentino y Bandera en la Formación Gaiman (Haller y Mendía, 1980) (Oligoceno Superior-Mioceno Inferior). Malumián y Náñez (1998), en función del foraminífero Transversigerina en la base de la secuencia transgresiva patagoniana, expusieron un sincronismo en dicha ingresión marina de edad no mayor que el Oligoceno cuspidal, correlacionando la Formación Gran Bajo del Gualicho con las formaciones Chenque, Centinela, Gaiman y Monte León.
Del Río (2004) definió la Asociación de Moluscos NVG, reconociéndola en los niveles superiores de la Formación Chenque, en las formaciones Gaiman y Vaca Mahuida y en la sección inferior de la Formación Gran Bajo del Gualicho, esta última incluida aquí en el Miembro Saladar nov. (Fig. texto 5; Tabla 1). Sobre la base del contenido palinológico de los horizontes superiores de la Formación Chenque (Barreda y Palamarczuk, 2000a, b, c; Barreda, 2002) y la presencia de los géneros Monophoraster, Amplaster, Abertella, Patinopecten y Nodipecten la Asociación NVG fue ubicada en el Mioceno Temprano alto-Mioceno Medio bajo (Del Río, 2004). En este trabajo se amplía el listado de géneros exclusivos de dicha asociación con el hallazgo en el Miembro Saladar nov. de Anadara Gray, Tawera Marwick, Spirocolpus Finlay, Siphocypraea Heilprin, Magnatica Marwick, Eudolium Dall, Chicoreus (Chicoreus) Montfort y Mitra (Fusimitra) Conrad y con la inclusión de Amusium Röding, Purpurocardia Maxwell, Polystira Woodring, Ficus Röding, Sconsia Gray, Austroimbricaria Olivera y Camacho y Conus Linnaeus, géneros citados para otras asociaciones de Patagonia (Tabla 1), extendiendo así su distribución estratigráfica. La presencia de Amusium (Mioceno Temprano-Reciente), Nodipecten (Mioceno Medio-Reciente), Purpurocardia (Oligoceno Superior-Reciente), Tawera (Mioceno Temprano-Reciente), Dosinia (Dosinia) (OligocenoReciente), Siphocypraea (Oligoceno-Pleistoceno), Eudolium (Mioceno Temprano-Reciente), Austroimbricaria (Mioceno Temprano), Polystira (Mioceno Temprano-Reciente), Monophoraster (Mioceno Temprano alto-Mioceno Tardío bajo) y Abertella (Mioceno) confirma la edad miocena temprana alto-miocena media baja propuesta por Del Río (2004) para dicha asociación.

TABLA 1. CORRELACIÓN ENTRE LA FORMACIÓN GRAN BAJO DEL GUALICHO Y OTRAS FORMACIONES MARINAS NEÓGENAS DE LA PATAGONIA ARGENTINA.

\begin{tabular}{lcclc}
\hline \multicolumn{1}{c}{ Edad } & $\begin{array}{c}\text { Cuenca Golfo San } \\
\text { Jorge }\end{array}$ & $\begin{array}{c}\text { Cuenca Península } \\
\text { Valdés }\end{array}$ & \multicolumn{1}{c}{$\begin{array}{c}\text { Cuenca Colorado } \\
\text { (margen sur) }\end{array}$} & \multicolumn{1}{c}{ Cuenca Neuquina } \\
Mioceno Tardío bajo & - & Fm. Puerto Madryn & $\begin{array}{l}\text { Fm. Gran Bajo del Gualicho. } \\
\text { Miembro Arriola nov. }\end{array}$ \\
$\begin{array}{l}\text { Mioceno Temprano alto- } \\
\text { Mioceno Medio bajo }\end{array}$ & $\begin{array}{l}\text { Fm. Chenque } \\
\text { (sección superior) }\end{array}$ & $\begin{array}{l}\text { Fm. Gaiman (estratos } \\
\text { con Venericor) }\end{array}$ & $\begin{array}{l}\text { Fm. Gran Bajo del Gualicho. } \\
\text { Miembro Saladar nov. }\end{array}$ & $\begin{array}{l}\text { Fm. Vaca Mahuida } \\
\text { (estratos con Venericor) }\end{array}$ \\
\hline
\end{tabular}




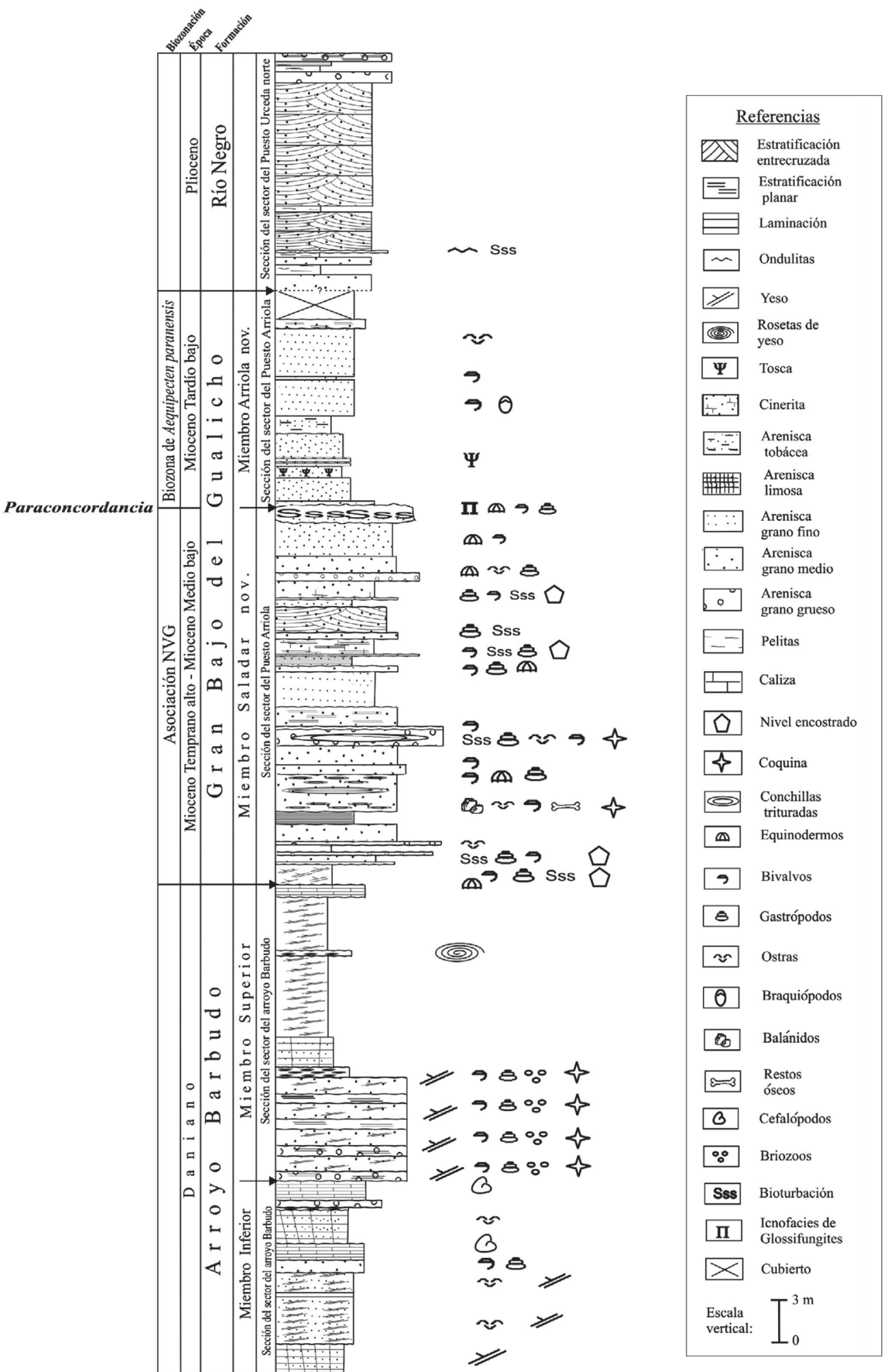

Fig. texto 5. Perfil integrado de las sedimentitas terciarias aflorantes en el área del Gran Bajo y Salinas del Gualicho. 


\section{2. Miembro Arriola nov. Areniscas tobáceas, cineritas, pelitas, tosca}

\subsubsection{Localidad tipo, distribución areal y rela- ciones estratigráficas}

Se propone este nombre para identificar las sedimentitas de origen marino con elevado aporte piroclástico pertenecientes a la Formación Gran Bajo del Gualicho, comprendidas entre el techo del Miembro Saladar nov. y la base de la Formación Río Negro. Se designa como localidad tipo el área de las Salinas del Gualicho constituida por los niveles superiores de las barrancas que afloran en el Puesto Arriola ( $\left.40^{\circ} 17^{\prime} \mathrm{S} ; 65^{\circ} 11^{\prime} \mathrm{O}\right)$, a partir de la cota de 51 m s.n.m. (Fig. texto 3, perfil tipo: B: $40^{\circ} 19^{\prime}$ 'S; $\left.65^{\circ} 07^{\prime} \mathrm{O}\right)$. El Miembro Arriola nov. apoya paraconcordantemente sobre el Miembro Saladar nov., aflorando en el área de las Salinas del Gualicho y en la región situada al este de la Ruta No. 2. Sus sedimentos conforman la parte más alta de las barrancas que rodean las depresiones, constituyendo el tope de las secuencias o subyaciendo a la Formación Río Negro luego de una discordancia erosiva. El espesor varía entre 8 y $21 \mathrm{~m}$.

\subsubsection{Litología y ambiente de los depósitos}

Se distingue por el predominio de areniscas tobáceas friables grises o marrones, de 3 a 3,50 m de espesor, que alternan con cineritas blancas (espesor: 0,20 a $0,40 \mathrm{~m}$ ), pelitas estériles (espesor: $1 \mathrm{a}$ $2 \mathrm{~m}$ ) y tosca (generalmente en forma de muñecos). Las estructuras sedimentarias son muy escasas, solo estratificación planar gruesa en algunas de las areniscas tobáceas (hacia los estratos superiores) o vestigios de laminación en las pelitas y cineritas. Esta sucesión litológica indicaría un ambiente somero afectado por lluvias de cenizas volcánicas, tal vez correspondiente a una albúfera salobre de planicie costera, a juzgar por la baja diversidad de especies y la presencia de grandes ostras en posición de vida asociadas al tope de la secuencia. La presencia de Pholadidea Turton en los términos basales de este miembro indicaría la existencia de un sustrato litificado al comienzo del ciclo, evidenciando el hiato existente con el Miembro Saladar nov. subyacente.

\subsubsection{Contenido fosilífero}

En este miembro los fósiles son poco diversificados; la fauna se encuentra transportada a excepción de los Crassostreinae de los niveles más altos que son considerados como una representación residual. Sus principales componentes son bivalvos; en forma subordinada, braquiópodos, balánidos y escasos moldes de gastrópodos. En los estratos inferiores se han determinado Pholadidea aff. P. patagonica (Philippi), Pholadidea sp., Brachidontes (Brachidontes) ortmanni Chiesa, Parma y Camacho, Pododesmus (Monia) atlantica sp. nov., Zygochlamys rizzoloi sp. nov., Cubitostrea alvarezii (d'Orbigny), Cubitostrea delrioi sp. nov. y Dosinia (Dosinia) salarensis sp. nov. Hacia los términos intermedios la diversidad disminuye, aquí se han hallado Crassostrea patagonica (d'Orbigny), Cubitostrea alvarezi, Cubitostrea delrioi sp. nov. y Zygochlamys rizzoloi sp. nov. En los estratos superiores solo se han encontrado numerosos ejemplares de Crassostrea patagonica, muy bien preservados y en posición de vida, con las valvas izquierdas reclinadas sobre el sustrato.

\subsubsection{Edad y correlaciones}

Hasta el momento, los estudios realizados en el área por diversos autores permiten observar seis criterios respecto a la identidad de las sedimentitas que en este trabajo se incluyen en el Miembro Arriola nov.: inclusión de los 'estratos superiores' de la Formación Gran Bajo del Gualicho dentro del 'Entrerriense', sin denominación formal (Rizzolo, 1967; Camacho, 1967); inclusión de las sedimentitas en la 'sección superior' de la Formación Gran Bajo del Gualicho, correlacionándolas con la Formación Puerto Madryn (Camacho, 1987); utilización del nombre Formación Puerto Madryn para incluir al Miembro Arriola nov. (Cortés, 1981; Camacho, 1987; Busteros et al., 1998); correlación de la Formación Puerto Madryn con las sedimentitas que se incluyen en este trabajo dentro del Miembro Arriola nov. (Del Río, 1988, 2000) y constituyendo la Formación Gran Bajo del Gualicho, correlacionada con el 'Entrerriense' (s.l.). (Aguirre-Urreta y Farinati, 1997; Aceñolaza, 2000) o mencionando fauna 'Entrerriense' en la sección superior de la Formación Gran Bajo del Gualicho (Del Río, 1990).

En el Miembro Arriola nov. la única especie común con las formaciones Puerto Madryn y Paraná es Cubitostrea alvarezi. Cinco de los siete géneros hallados están presentes en la Formación Puerto Madryn, pero solo Zygochlamys tiene importancia bioestratigráfica dado que Zygochlamys actinodes (Sowerby) marca la base de la biozona de Aequipecten paranensis del Río, característica de dicha 
formación. Dosinia (Dosinia), Brachidontes y Crassostrea si bien se encuentran representados en esta biozona no son exclusivos de la misma, por lo que no se pueden utilizar como indicadores de su presencia; no obstante, debido a sus relaciones bioestratigráficas y a que se observa un cambio total en la asociación faunística respecto al miembro subyacente, se postula la correlación del Miembro Arriola nov. con el 'Entrerriense' representado por la Formación Puerto Madryn (Haller, 1978) (Fig. texto 5; Tabla 1). La biozona de Aequipecten paranensis se ubicó originalmente en el Mioceno Medio (Del Río, 1988, 1990, 1991). Posteriormente, Scasso et al. (1999), sobre la base de datos isotópicos, ubicaron a la Formación Puerto Madryn en el Mioceno Tardío basal (Tortoniano medio, $10 \pm 0,3 \mathrm{Ma}$ ) con valores aproximados a los previamente referidos por Zinsmeister et al. (1981) para estas sedimentitas (9,45 Ma). Las edades radiométricas ubicarían la fauna 'Entrerriense' en el primer pulso cálido del Tortoniano propuesto por Wright et al. (1991) (Del Río, 2000). La edad miocena tardía de la Formación Puerto Madryn también ha sido confirmada por la presencia de los palinomorfos Tubulifloridites pleistocenicus Martín y Tubulifloridites simplis Martín (Palazzesi y Barreda, 2004). En función de la biozona de Aequipecten paranensis y la presencia de Pododesmus (Monia) Gray, cuyo registro más antiguo es en el Mioceno Tardío de Nueva Zelanda (Beu y Maxwell, 1990), se asigna al Miembro Arriola nov., la edad miocena tardía baja.

\section{Composición y afinidades de los moluscos de la Formación Gran Bajo del Gualicho}

La malacofauna fósil de la Formación Gran Bajo del Gualicho (Tabla 2) está compuesta por 35 géneros, de los cuales $50 \%$ son gastrópodos, $47 \%$ bivalvos y $3 \%$ escafópodos. Se identificaron 41 especies, que incluyen 17 (41,5\%) nuevas (Apéndice. Paleontología). Entre los bivalvos Anadara, Glycymerita Finlay y Marwick, Cubitostrea Sacco, Zygochlamys Ihering, Nodipecten Dall, Venericor (Neovenericor) Rossi de García y Levy, Tawera y Dosinia (Dosinia) Scopoli se encuentran altamente representados; en particular Venericor (Neovenericor) austroplata se ha hallado profusamente en el Miembro Saladar nov. Los registros de Anadara, Amusium, Purpurocardia, Tawera, Spirocolpus y Polystira son los más antiguos para Argentina. Tawera canalei sp. nov. constituye la primera mención del género para el Cenozoico sudamericano y Eudolium lissiei sp. nov. la primera cita de la Familia Tonnidae para la República Argentina. Las especies Zygochlamys rizzoloi sp. nov., Magnatica hansi sp. nov., Chicoreus (Chicoreus) guadalupei sp. nov., Mitra (Fusimitra)

TABLA 2. MALACOFAUNA PRESENTE EN LAASOCIACIÓN NVG DEL MIEMBRO SALADAR NOV. CITADA PARA OTRAS ASOCIACIONES DE PATAGONIA (DEL RÍO 1988, 2004).

\begin{tabular}{ll}
\hline \multicolumn{1}{c}{ Género } & $\begin{array}{c}\text { Asociaciones de moluscos } \\
\text { en Patagonia }\end{array}$ \\
\hline Iheringinucula Del Río y Camacho & $\mathrm{JR} / \mathrm{RSP}$ / PA \\
Glycymerita Finlay y Marwick & $\mathrm{PA}$ \\
Amusium Röding & Aequipecten paranensis \\
Purpurocardia Maxwell & Aequipecten paranensis \\
Hedecardium Marwick & $\mathrm{PA}$ \\
Dosinia Scopoli & Aequipecten paranensis \\
Panopea Menard de la Groye & $\mathrm{PP} /$ Aequipecten paranensis \\
Spirocolpus Finlay & Aequipecten paranensis \\
Ficus Röding & $\mathrm{JR} / \mathrm{RSP}$ / PA \\
Sconsia Gray & $\mathrm{RSP}$ \\
Austroimbricaria Olivera y Camacho & $\mathrm{RSP} / \mathrm{PA}$ \\
Conus Linné & $\mathrm{RSP}$ \\
Polystira Woodring & Aequipecten paranensis \\
\hline
\end{tabular}

PP: Asociación Panopea sierrana-Parinomya patagonensis; RSP: Asociación Reticulochlamys zinsmeisteri-Struthiolarella patagonensis-Pleuromeris cruzensis; PA: Asociación Pseudoportlandia glabra-Antimelatoma quemadensis; JR: Asociación Jorgechlamys centralis-Reticulochlamys borjasensis. 
carlosi sp. nov. y Siphocypraea posei representan la primera mención de los géneros en el país, mientras que Sconsia magdai sp. nov. constituye la primera mención válida del género para Argentina.

En el Miembro Saladar nov. se han hallado 30 géneros y 35 especies ( $51 \%$ gastrópodos, $46 \%$ bivalvos y $3 \%$ escafópodos). La fauna presenta mayor afinidad con las que integran las formaciones Monte León (Mioceno Temprano) y Chenque (Mioceno Temprano alto-Mioceno Medio bajo), compartiendo con la primera el $48 \%$ de los géneros y con la segunda el 41\%. La Formación San Julián (Oligoceno) presenta solo el $24 \%$ de géneros en común (Tabla $3)$. A nivel específico, tanto con la Formación Chenque como con la Formación Monte León se han hallado el $12 \%$ de las especies en común (con la primera: Glycymerita camaronesia, Nodipecten salis, Venericor (Neovenericor) austroplata y $\mathrm{Pa}$ nopea quemadensis; con la segunda: Glycymerita cuevensis, Panopea quemadensis, Valdesia (Juliania) seudocollaris y Perissodonta ameghinoi, mientras que con la Formación San Julián se ha hallado solo una (Panopea quemadensis).

La malacofauna del Miembro Arriola está constituida por 7 géneros y 8 especies de bivalvos. A nivel genérico (Tabla 4), este miembro presenta mayor afinidad con las formaciones Puerto Madryn (Mioceno Tardío bajo) y Paraná (Mioceno Tardío), donde se encuentran representados el $71 \%$ y el $57 \%$ respectivamente. La representación específica es baja, hallándose en ambas formaciones solo Cubitostrea alvarezii.

Las asociaciones de moluscos de la Formación Gran Bajo del Gualicho se han comparado también con las malacofaunas cenozoicas chilenas de las formaciones Guadal (Región de Aisén, Oligoceno Superior-Mioceno Temprano; Frassinetti y Covacevich, 1999) y Navidad (Chile central; Covacevich y Frassinetti, 1980; Frassinetti y Covacevich, 1984, 1993, 1999; Nielsen, 2003; Nielsen y Frassinetti, 2007) (Tabla 5). La Formación Navidad ha sido datada por medio de foraminíferos planctónicos (zonas N16 y N19) para el Mioceno Tardío-Plioceno Temprano (Encinas et al., 2006; Finger et al., 2007; Encinas et al., 2008); sin embargo, los fósiles asociados se han datado para el Oligoceno Tardío-Mioceno Temprano (De Vries y Frassinetti, 2003; Nielsen y Glodny, 2006; Suárez et al., 2006; Finger et al., 2007) sugiriendo un retrabajo de la fauna (Finger et al., 2007). El 30\% de los géneros del Miembro
Saladar nov. han sido citados para la Formación Navidad, mientras que el 10\% se encuentran en la Formación Guadal (Frassinetti y Covacevich, 1999). A nivel específico solo están representados Ficus distans y Perissodonta ameghinoi, respectivamente. En común con el Miembro Arriola nov. se han encontrado Brachidontes y Pholadidea, ambos en la Formación Guadal (Frassinetti y Covacevich, 1999).

\section{Inferencias paleoclimáticas e implicancias biogeográficas en la Formacion Gran Bajo del Gualicho}

En el Miembro Saladar nov. la presencia de Siphocypraea, Sconsia, Eudolium, Ficus, Chicoreus (Chicoreus), Mitra (Fusimitra), Conus, Polystira, Nodipecten y Amusium, taxones afines a los pertenecientes a típicas asociaciones cálidas neógenas del Caribe (Woodring, 1928, 1970-82; Vokes, 1965, 1974, 1986; Petuch, 1988; Dolin, 1991; Rossbach y Carter, 1991; Schmelz, 2001), permiten estimar una temperatura de las aguas superior a la actual para la misma área y superior a la acaecida durante el mismo lapso temporal en el resto de la Patagonia, tal vez del tipo templado-cálida, ya que involucra algunas formas weddellianas (templado-frías) como Glycymerita y Perissodonta Martens. En efecto, el registro bioestratigráfico atlántico patagónico señala para esa época una diferenciación en franjas climáticas (Barreda y Palamarczuk, 2000a). Así, para el Oligoceno cuspidal- Mioceno Temprano (Náñez, 1988; Barreda y Palamarczuk, 2000c) la Formación Monte León, que se desarrolla al sur del Macizo del Deseado, evidencia un desmejoramiento climático que en el caso de los foraminíferos está representado por la asociación Martinottiella-Spirosigmoilinella (Náñez, 1988). Las asociaciones esporopolínicas señalan también un comienzo de diferenciación latitudinal manifestado por la aparición de géneros y especies afines a Lyparophyllum, que sugiere un desarrollo en áreas templado-frías (Barreda y Palamarczuk, 2000a). Al norte del Macizo del Deseado los afloramientos del Oligoceno cuspidal-Mioceno Medio bajo permiten inferir la presencia de mayor humedad y temperatura (Barreda y Palamarczuk, 2000b). Las asociaciones esporopolínicas del Mioceno Temprano alto-Mioceno Medio bajo, identificadas en la parte superior de la Formación Chenque, evidencian un clima húmedo y templado-cálido con un avance de elementos tropicales que sugieren 
TABLA 3. DISTRIBUCIÓN ESTRATIGRÁFICA DE LAS ESPECIES DE MOLUSCOS PRESENTES EN EL ÁREA DEL GRAN BAJO Y SALINAS DEL GUALICHO.

\begin{tabular}{|c|c|c|}
\hline \multirow[t]{2}{*}{ Especie } & \multicolumn{2}{|c|}{ Formación Gran Bajo del Gualicho } \\
\hline & Miembro Saladar & Miembro Arriola \\
\hline Iheringinucula sp. & $\mathrm{X}$ & -- \\
\hline Anadara australis sp. nov. & $\mathrm{X}$ & -- \\
\hline Glycymerita cuevensis (Ihering) & $\mathrm{X}$ & -- \\
\hline Glycymerita camaronesia (Ihering) & $\mathrm{X}$ & -- \\
\hline Brachidontes (Brachidontes) ortmanni Chiesa, Parma y Camacho & -- & $\mathrm{X}$ \\
\hline Crassostrea patagonica (d’Orbigny) & $\mathrm{X}$ & $\mathrm{X}$ \\
\hline Cubitostrea alvarezii (d'Orbigny) & -- & $\mathrm{X}$ \\
\hline Cubitostrea delrioi sp. nov. & -- & $\mathrm{X}$ \\
\hline Amusium rorii sp. nov. & $\mathrm{X}$ & -- \\
\hline Zygochlamys rizzoloi sp. nov. & -- & $\mathrm{X}$ \\
\hline Nodipecten salis del Río & $\mathrm{X}$ & -- \\
\hline Pododesmus (Monia) atlantica sp. nov. & -- & $\mathrm{X}$ \\
\hline Lucinidae sp. & $\mathrm{X}$ & -- \\
\hline Venericor (Neovenericor) austroplata Gardner y Bowles & $\mathrm{X}$ & -- \\
\hline Purpurocardia sp. & $\mathrm{X}$ & -- \\
\hline 'Hedecardium' sp. 1 & $\mathrm{X}$ & -- \\
\hline 'Hedecardium' sp. 2 & $\mathrm{X}$ & -- \\
\hline Tawera canalei sp. nov. & $\mathrm{X}$ & -- \\
\hline Dosinia (Dosinia) salarensis sp. nov. & $\mathrm{X}$ & $\mathrm{X}$ \\
\hline Panopea aff. Panopea nucleus (Ihering) & $\mathrm{X}$ & -- \\
\hline Panopea cf. quemadensis Ihering & $\mathrm{X}$ & -- \\
\hline Pholadidea aff. patagonica (Philippi) & -- & $\mathrm{X}$ \\
\hline Valdesia (Juliania) aff. $V .(J$.$) seudocollaris Morra y Del Río$ & $\mathrm{X}$ & -- \\
\hline 'Spirocolpus' adapicis sp. nov. & $\mathrm{X}$ & -- \\
\hline Torcula magna sp. nov. & $\mathrm{X}$ & -- \\
\hline Perissodonta ameghinoi (Ihering) & $\mathrm{X}$ & -- \\
\hline Siphocypraea posei (Figueiras) & $\mathrm{X}$ & -- \\
\hline Magnatica hansi sp. nov. & $\mathrm{X}$ & -- \\
\hline Eudolium lissiei sp. nov. & $\mathrm{X}$ & -- \\
\hline Ficus distans (Sowerby) & $\mathrm{X}$ & -- \\
\hline Sconsia magdai sp. nov. & $\mathrm{X}$ & -- \\
\hline Chicoreus (Chicoreus) guadalupei sp. nov. & $\mathrm{X}$ & -- \\
\hline Penion patagonensis sp. nov. & $\mathrm{X}$ & -- \\
\hline Mitra (Fusimitra) carlosi sp. nov. & $\mathrm{X}$ & -- \\
\hline Austroimbricaria brugnii sp. nov. & $\mathrm{X}$ & -- \\
\hline $\begin{array}{l}\text { Adelomelon posei Scarabino, Martínez, Del Río, Oleinik, Cama- } \\
\text { cho y Zinsmeister }\end{array}$ & $\mathrm{X}$ & -- \\
\hline Pachycymbiola camachoi del Río y Martínez & $\mathrm{X}$ & -- \\
\hline Pachycymbiola arriolensis del Río y Martínez & $\mathrm{X}$ & -- \\
\hline Conus aff. infulatus Hoerle & $\mathrm{X}$ & -- \\
\hline Polystira cingula sp. nov. & $\mathrm{X}$ & -- \\
\hline Dentalium sp. & $\mathrm{X}$ & -- \\
\hline
\end{tabular}


TABLA 4. DISTRIBUCIÓN DE GÉNEROS DE MOLUSCOS PRESENTES EN EL MIEMBRO SALADAR NOV. DE LA FORMACIÓN GRAN BAJO DEL GUALICHO Y EN OTRAS FORMACIONES DEL CENOZOICO DE LA PATAGONIA ARGENTINA.

\begin{tabular}{|c|c|c|c|}
\hline Género & $\begin{array}{l}\text { Formación } \\
\text { San Julián }\end{array}$ & $\begin{array}{c}\text { Fomación } \\
\text { Monte León }\end{array}$ & $\begin{array}{r}\text { Formación } \\
\text { Chenque }\end{array}$ \\
\hline Iheringinucula Del Río y Camacho & $\mathrm{X}$ & $\mathrm{X}$ & $\mathrm{X}$ \\
\hline Glycymerita Finlay Marwick & $\mathrm{X}$ & $\mathrm{X}$ & $\mathrm{X}$ \\
\hline Amusium Röding & -- & -- & -- \\
\hline Nodipecten Dall & -- & -- & $\mathrm{X}$ \\
\hline Venericor (Neovenericor) Rossi de García y Levi & -- & -- & $\mathrm{X}$ \\
\hline Purpurocardia Maxwell & -- & -- & -- \\
\hline Hedecardium Marwick & -- & -- & $\mathrm{X} ?$ \\
\hline Dosinia (Dosinia) Scopoli & $\mathrm{X}$ & $\mathrm{X}$ & \\
\hline Panopea Menard de la Groye & $\mathrm{X}$ & $\mathrm{X}$ & $\mathrm{X}$ \\
\hline Valdesia (Juliania) Morra y Del Río & $\mathrm{X}$ & $\mathrm{X}$ & -- \\
\hline Spirocolpus Finlay & -- & -- & -- \\
\hline Torcula Gray & -- & -- & $\mathrm{X}$ ? \\
\hline Perisodonta Martens & $\mathrm{X}$ & $\mathrm{X}$ & $\mathrm{X}$ \\
\hline Ficus Röding & $\mathrm{X}$ & $\mathrm{X}$ & -- \\
\hline Sconsia Gray & $\mathrm{X}$ & -- & $\mathrm{X}$ \\
\hline Penion Fisher & -- & $\mathrm{X}$ & $\mathrm{X}$ \\
\hline Austroimbricaria Olivera y Camacho & -- & $\mathrm{X}$ & -- \\
\hline Adelomelon Dall & -- & $\mathrm{X}$ & -- \\
\hline Pachycymbiola Ihering & -- & $\mathrm{X}$ & $\mathrm{X}$ \\
\hline Conus Linnaeus & -- & -- & $\mathrm{X}$ \\
\hline Polystira Woodring & -- & -- & -- \\
\hline
\end{tabular}

TABLA 5. DISTRIBUCIÓN DE GÉNEROS DE MOLUSCOS PRESENTES EN EL MIEMBRO ARRIOLA NOV. DE LA FORMACIÓN GRAN BAJO DEL GUALICHO Y EN OTRAS FORMACIONES DEL CENOZOICO DE LA PATAGONIA ARGENTINA.

\begin{tabular}{lcc}
\hline Género & Formación Puerto Madryn & Formación Paraná \\
\hline Brachidontes (Brachidontes) Swainson & $\mathrm{X}$ & $\mathrm{X}$ \\
Crassostrea Sacco & $\mathrm{X}$ & $\mathrm{X}$ \\
Cubitostrea Sacco & $\mathrm{X}$ & $\mathrm{X}$ \\
Zygochlamys Ihering & $\mathrm{X}$ & -- \\
Dosinia (Dosinia) Scopoli & $\mathrm{X}$ & $\mathrm{X}$ \\
\hline
\end{tabular}

TABLA 6. DISTRIBUCIÓN DE GÉNEROS DE MOLUSCOS PRESENTES EN LA FORMACIÓN GRAN BAJO DEL GUALICHO Y EN LAS FORMACIONES CHILENAS NAVIDAD Y GUADAL.

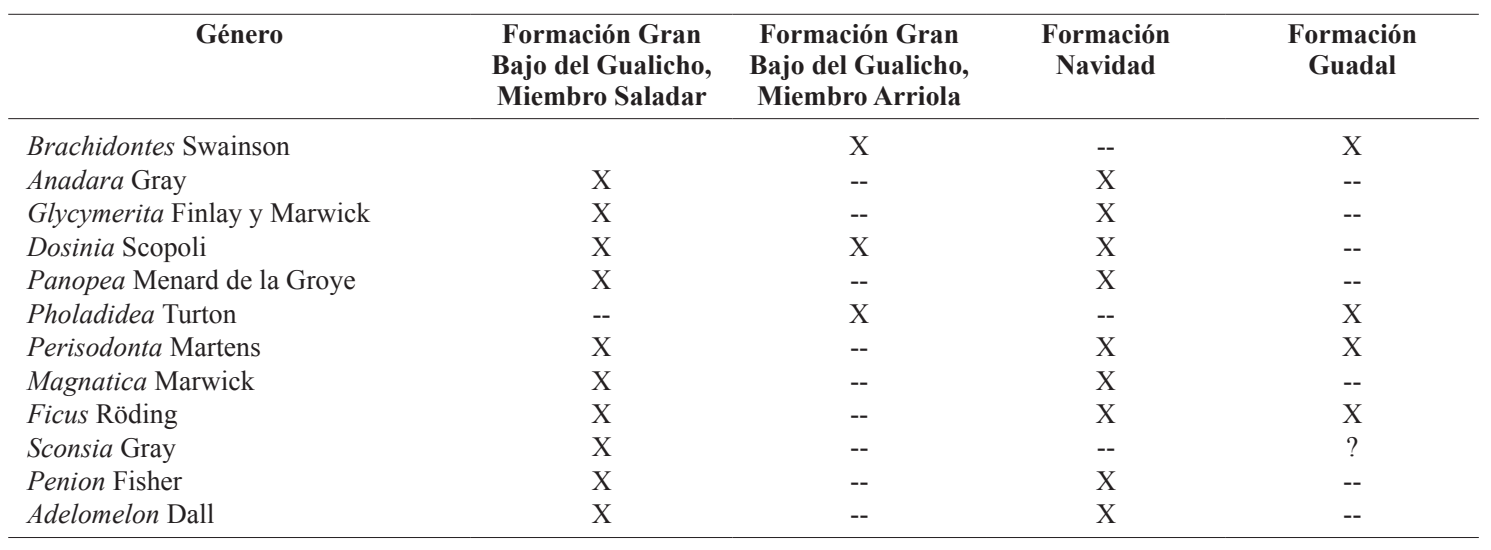


un incremento en la temperatura hasta alcanzar un clima cálido y húmedo (Barreda y Palamarczuk, 2000a; Barreda, 1996, 2002). Este mejoramiento climático se refleja también en la fauna del Miembro Saladar nov. donde, junto con los taxones típicos de aguas cálidas, se observa un profuso desarrollo de Venericor (Neovenericor). El subgénero, que se distribuye en la Patagonia oriental al norte del paralelo $46^{\circ}$, presenta un aumento gradual en el número poblacional de individuos hacia el norte, alcanzando su máxima representación en el área de estudio, donde se registran diversos niveles con abundantes ejemplares de Neovenericor. Este hecho se interpreta como una progresiva mejora en sus condiciones de desarrollo, en función de prosperidad climática, de manera concomitante con la disminución latitudinal. Su asociación con el género Abertella, ampliamente distribuido durante el Mioceno en el Atlántico medio y costa SE de los Estados Unidos, América Central, islas del Golfo de México y Brasil (Martínez et al., 2005) reforzaría esta conclusión. La fauna del Miembro Saladar nov. constituye una evidencia más respecto a la diferenciación en franjas climáticas postulada para Patagonia a partir del Oligoceno Tardío-Mioceno Temprano, explicando la principal diferencia observada en relación con otras formaciones cenozoicas argentinas atribuidas a la misma edad, que presentan un predominio de elementos de aguas templado-frías (Del Río, 2004) indicadores de condiciones de menor temperatura para las latitudes más altas.

En el Miembro Arriola nov. la presencia de la biozona de Aequipecten paranensis permite extender el área abarcada por la Provincia Valdesiana (Martínez y Del Río, 2002) hasta las Salinas del Gualicho. Si bien en la Formación Puerto Madryn la presencia de una asociación paratropical (en el sentido de Petuch, 1988), permitió estimar temperaturas de las aguas superiores a las actuales para las mismas latitudes, en el caso del Miembro Arriola, debido a la escasa fauna hallada, no se han podido efectuar inferencias de temperatura.

\section{Conclusiones}

- Se acota la edad de la Formación Gran Bajo del Gualicho al lapso Mioceno Temprano altoMioceno Tardío bajo y se establecen dentro de dicha formación los Miembros Saladar nov. y Arriola nov. separados por una paraconcordancia.
- La sucesión litológica del Miembro Saladar nov. evidencia un ambiente transgresivo de aguas someras con una evolución de facies desde depósitos de plataforma hasta típicos depósitos de playa. La presencia de 'hardgrounds' sugiere diferentes estadios de variaciones rápidas del nivel del mar durante la depositación del miembro.

- La litología asociada al Miembro Arriola nov. indica un ambiente somero afectado por lluvias de cenizas volcánicas.

- Se describen 17 especies nuevas para la Formación Gran Bajo del Gualicho: Anadara australis sp. nov., Cubitostrea delrioi sp. nov., Amusium rorii sp. nov., Zygochlamys rizzoloi sp. nov., Pododesmus (Monia) atlantica sp. nov., Tawera canalei sp. nov., Dosinia (Dosinia) salarensis sp. nov., 'Spirocolpus' adapicis sp. nov., Torcula magna sp. nov., Magnatica hansi sp. nov., Eudolium lissiei sp. nov., Sconsia magdai sp. nov., Chicoreus (Chicoreus) guadalupei sp. nov., Penion patagonensis sp. nov., Mitra (Fusimitra) carlosi sp. nov., Austroimbricaria brugnii sp. nov. y Polystira cingula sp. nov.

- Se asigna el Miembro Saladar nov. al Mioceno Temprano alto-Mioceno Medio bajo y se correlaciona con la sección superior de la Formación Chenque y con las capas portadoras de Venericor de las formaciones Gaiman y Vaca Mahuida.

- Se amplía la composición de la Asociación NVG con la inclusión de los géneros exclusivos Siphocypraea, Magnatica, Eudolium, Chicoreus (Chicoreus), Mitra (Fusimitra), Anadara y Tawera y de los géneros Amussium, Spirocolpus, Purpurocardia, Polystira, Ficus, Sconsia, Austroimbricaria y Conus.

- La fauna del Miembro Saladar nov. está constituida por la asociación: Valdesia (Juliania) aff. seudocollaris, 'Spirocolpus' adapicis sp. nov., Torcula magna sp. nov., Perisodonta ameghinoi, Siphocypraea posei, Magnatica hansi sp. nov., Eudolium lissiei sp. nov., Ficus distans, Sconsia magdai sp. nov., Chicoreus (Chicoreus) guadalupei sp. nov., Penion patagonensis sp. nov., Mitra (Fusimitra) carlosi sp. nov., Austroimbricaria brugnii sp. nov., Adelomelon posei, Pachycymbiola camachoi, Pachycymbiola arriolensis, Conus aff. infulatus, Polystira cingula sp. nov., Venericor (Neovenericor) austroplata, Iheringinucula sp., Anadara australis sp. nov., Glycymerita cuevensis, Glycymerita camaronesia, Amusium rorii sp. nov., 
Nodipecten salis, Lucinidae sp., Purpurocardia sp., 'Hedecardium' sp. 1, 'Hedecardium' sp. 2, Tawera canalei sp. nov., Dosinia (Dosinia) salarensis sp. nov., Panopea aff. nucleus, Panopea cf. quemadensis, Dentalium sp., Abertella gualichensis y Monophoraster darwini. Esta fauna es más afín con las de las formaciones argentinas Monte León y Chenque, compartiendo con la primera el $48 \%$ de los géneros y con la segunda el $41 \%$. Las formaciones chilenas Navidad y Guadal presentan respectivamente el $30 \%$ y el $10 \%$ de los géneros en común.

- Siphocypraea, Magnatica, Eudolium, Chicoreus (Chicoreus) y Mitra (Fusimitra) son citados por primera vez para Argentina. Anadara, Amusium, Purpurocardia, Tawera, Spirocolpus y Polystira presentan su registro más antiguo para el país, mientras que Tawera canalei $\mathrm{sp}$. nov. constituye la primera mención del género para el Cenozoico sudamericano.

- La fauna del Miembro Saladar nov. constituye una evidencia más respecto a la diferenciación en franjas climáticas postulada para Patagonia a partir del Oligoceno Tardío-Mioceno Temprano, estimándose para el Atlántico sudoccidental una temperatura de las aguas templado-cálida.

- Se correlaciona el Miembro Arriola nov. con la Formación Puerto Madryn y se asigna al Mioceno Tardío bajo. La biozona de Aequipecten paranensis permite extender el área abarcada por la Provincia Valdesiana hasta las Salinas del Gualicho. En este miembro, debido a la escasa fauna hallada, no se han podido efectuar inferencias paleoclimáticas.

- La fauna del Miembro Arriola nov. está caracterizada por Brachidontes (Brachidontes) ortmanni, Pododesmus (Monia) atlantica sp. nov., Crassostrea patagonica, Cubitostrea alvarezii, Cubitostrea delrioi sp. nov., Zygochlamys rizzoloi sp. nov., Tawera canalei sp. nov., Dosinia (Dosinia) salarensis sp. nov. y Pholadidea aff. patagonica. Presenta mayor afinidad con aquellas de las formaciones Puerto Madryn y Paraná, donde se hallan representados el $71 \%$ y el $57 \%$ de los géneros, respectivamente. El subgénero Pododesmus (Monia) se cita por primera vez para la República Argentina.

\section{Agradecimientos}

El presente estudio se expone como síntesis parcial de Tesis Doctoral (Universidad de Buenos Aires, Facultad de
Ciencias Exactas y Naturales, área de Ciencias Geológicas). Se expresa el mayor agradecimiento al Dr. H.H. Camacho y a la Dra. C.J. Del Río por efectuar la dirección; a los jurados, Dres. E. Bellosi, M. Griffin y B. Aguirre Urreta y a los árbitros de la Revista, Dres. E. Pérez, S. Nielsen y T. DeVries, por sus comentarios y apreciaciones sobre el manuscrito. Al Museo Paleontológico Bariloche por proporcionar, en préstamo, parte del material fósil utilizado y al Ing. C.M. Canale por financiar la casi totalidad de la investigación.

\section{Referencias}

Abbott, R. 1954. American Seashells. D. Van Nostrand Co. Inc., Princeton: 541 p. Nueva York.

Aceñolaza, F.G. 2000. La Formación Paraná (Mioceno medio): estratigrafía, distribución regional y unidades equivalentes. In El Neógeno de Argentina (Aceñolaza, F.G.; Herbst, R.; editors). Serie Correlación Geológica 14: 1-28. Tucumán.

Adams, H.; Adams, A. 1853. The genera of Recent Mollusca (John Van Voorst, London Reeve and Benham; editors) 1: 484 p. Londres.

Aguirre-Urreta, M.B. 1990. Nuevos crustáceos decápodos (Brachyura y Anomura) en el Terciario de Patagonia, Argentina. In Congreso Argentino de Paleontología y Bioestratigrafía, No. 5, Actas 1: 149-153. Tucumán.

Aguirre-Urreta, M.B.; Farinati, E.A. 1997. Paleobiogeografía de las faunas de moluscos marinos del Neógeno y Cuaternario del Atlántico Sudoccidental. Revista de la Sociedad Geológica de España 12: 93-112.

Andreis, R. 1965. Petrografía y paleocorrientes de la Formación Río Negro. Revista del Museo de La Plata (NS) 5: 245-310.

Angelucci, A.; Barbieri, M.; Brodtkorb, A.; Ciccacci, S.; Civitelli, G.; De Barrio, R.; Di Filipo, M.; Fredi, P.; Friedman, I.; Lombardi, S.; Schalamuk, A.; Toro, B. 1996. Morphology, geology and geochemistry of the 'Salar Gran Bajo del Gualicho' (Río Negro, Argentina). Geológica Romana 32: 107-139.

Barreda, V. 1996. Bioestratigrafía de polen y esporas de la Formación Chenque, Oligoceno tardío?-Mioceno de las provincias de Chubut y Santa Cruz, Patagonia, Argentina. Ameghiniana 33: 35-56.

Barreda, V. 2002. Palinofloras cenozoicas. In Congreso Geológico Argentino, No. 15, Relatorio (El Calafate). (Haller, M.J.; editor): Geología y Recursos Naturales de Santa Cruz 11: 545-567. Buenos Aires.

Barreda, V.; Palamarczuk, S. 2000a. Palinomorfos continentales y marinos de la Formación Monte León 
en su área tipo, Provincia de Santa Cruz, Argentina. Ameghiniana 37: 3-12.

Barreda, V.; Palamarczuk, S. 2000b. Palinoestratigrafía de los depósitos del Oligoceno Tardío-Mioceno en el área sur del Golfo San Jorge, Provincia de Santa Cruz, Argentina. Ameghiniana 37: 103-117.

Barreda, V.; Palamarczuk, S. 2000c. Estudio palinoestratigráfico del Oligoceno Tardío-Mioceno en secciones de la costa patagónica y plataforma continental argentina. In El Neógeno de Argentina (Aceñolaza, F.G.; Herbst, R.; editores). Serie Correlación Geológica 14: 103-138. Tucumán.

Bellosi, E. 1990. Formación Chenque: registro de la transgresión patagoniana (Terciario medio) de la Cuenca de San Jorge, Argentina. In Congreso Geológico Argentino No. 11, Actas 2: 57-60. San Juan.

Beu, A.G.; Maxwell, P.A. 1990. Cenozoic Mollusca of New Zealand. New Zealand Geological Survey, Paleontological Bulletin 58: 1-518.

Beurlen, K. 1944. Beiträge zur Stammgeschichte der Muscheln. Bayerische Akademie der Wissenschäftlich, Sitzungsberichte 1: 133-145.

Bieler, R.; Mikkelsen, P.M. 2006. Bivalvia-a look at the Branches. Zoological Journal of Linnean Society 148: 223-235.

Boreham, A. 1965. A revision of F.W. Hutton`s pelecypod species described in the Catalogue of Tertiary Mollusca and Echinodermata (1873). New Zealand Geological Survey, Paleontological Bulletin 37: 1-125.

Born, I. 1778. Index rerum Naturalium Musei Caesarei Vindobonensis, Pars Prima, Testacea. Officina Krausiana, Vindobona: 458 p. Viena.

Bouchet, P.; Rocroi, J.P. 2005. Classification and nomenclator of Gastropod families. Malacologia 47 (1-2): 1-397.

Bowles, E. 1939. Eocene and Paleocene Turritellidae of the Atlantic and Gulf Coastal Plain of North America. Journal of Paleontology 13: 267-336.

Broderip, W. 1834. Descriptions of several new species of Calyptraeidae. Proceedings of the Zoological Society of London 2: 35-40.

Brunet, R. 1995. New species of Mollusca from the Entrerriense Formation (Upper Miocene) of Chubut Province, Argentina and species not previously reported fromthis formation. Part I - Gastropoda and Scaphopoda. Tulane Studies in Geology and Paleontology 28 (1 -2): 1-56.

Buatois, L.; Mángano, M.G. 2000. Aplicaciones de la icnología en prospección de hidrocarburos y caracterización de reservorios. Boletín de Informaciones Petroleras: 64: 1-85.
Busteros, A.; Giacosa, R.; Lema, H. 1998. Hoja Geológica 4166-IV 'Sierra Grande'. 1:250.000. Boletín del Servicio de Geología y Minería de la República Argentina 241: 1-75.

CAE (Comité Argentino de Estratigrafía). 1992. Código Argentino de Nomenclatura Estratigráfica. Asociación Geológica Argentina Serie B (Didáctica y Complementaria) 20: 1-64.

Camacho, H.H. 1967. Las transgresiones del Cretácico superior y Terciario de la Argentina. Revista de la Asociación Geológica Argentina 22: 253-280.

Camacho, H.H. 1974. Bioestratigrafía de las formaciones marinas del Eoceno y Oligoceno de la Patagonia. Anales de la Academia Nacional de Ciencias Exactas, Físicas y Naturales 26: 39-57.

Camacho, H.H. 1987. Una asociación novedosa de moluscos terciarios del Gran Bajo del Gualicho, Provincia de Río Negro. Patagoniana 3: 3-9.

Camacho, H.H. 1995. La Formación Patagónica (F. Ameghino, 1894): Su actual significación estratigráfica y paleontológica. Anales de la Academia de Ciencias de Chile 5: 117-151.

Chiesa, J.O.;Parma, S.G.; Camacho, H.H. 1995. Invertebrados marinos de la Formación El Chacay (Eoceno), Provincia de Santa Cruz, Argentina. Sistemática y bioestratigrafía. Academia Nacional de Ciencias Exactas, Físicas y Naturales. Monografía 11: 17-68.

Conrad, T. 1855. Report of the United States and Mexican Boundary Survey. Proceedings of the Academy of Natural Sciences of Philadelphia 7: 1-261.

Cortés, J.N. 1981. Estratigrafía cenozoica y estructura al oeste de la Península de Valdés, Chubut. Consideraciones tectónicas y paleogeográficas. Revista de la Asociación Geológica Argentina 36: 424-445.

Covacevich, V.; Frassinetti, D. 1980. El género Ficus en el Mioceno de Chile central con descripción de $F$. gayana sp. nov. Gastropoda: Ficidae. Boletín del Museo Nacional de Historia Natural de Chile 37: 281-294.

Cox, L. 1959. Thoughts on the classification of the Gastropoda. Proceedings of the Malacological Society of London 33 (6): 239-261.

Cuvier, G. 1797. Tableau elementaire de l'historie naturelle des animaeux [des Mollusques]. Baudouin: 710 p. Paris.

Dall, W. 1889. A preliminary catalogue of the shell bearing marine mollusks and brachiopods of the southeastern coast of the United States. Bulletin of the United States Natural Museum 3: 1-212.

Dall, W. 1892. Contributions to the Tertiary fauna of Florida. Transactions of the Wagner Free Institute of Sciences 3 (6): 1219-1654. 
Del Río, C.J. 1988. Bioestratigrafía y cronoestratigrafía de la Formación Puerto Madryn (Mioceno Medio). Provincia del Chubut-Argentina. Anales de la Academia Nacional de Ciencias Exactas, Físicas y Naturales 40: 231-254.

Del Río, C.J. 1990. Composición, origen y significado paleoclimático de la malacofauna 'Entrerriense' (Mioceno medio) de la Argentina. Anales de la Academia Nacional de Ciencias Exactas, Físicas y Naturales 42: 205-224.

Del Río, C.J. 1991. Revisión sistemática de los bivalvos de la Formación Paraná (Mioceno Medio). Provincia de Entre Ríos-Argentina. Academia Nacional de Ciencias Exactas, Físicas y Naturales. Monografía 7: 1-93.

Del Río, C.J. 1992. Middle Miocene Bivalves of the Puerto Madryn Formation, Valdés Peninsule, Chubut Province, Argentina (Nuculidae-Pectinidae). Palaeontographica, Part. 1. Abteilung A 225: 1-57.

Del Río, C.J. 2000. Malacofauna de las formaciones Paraná y Puerto Madryn (Mioceno marino, Argentina): su origen, composición y significado bioestratigráfico. In El Neógeno de Argentina (Aceñolaza, F.G.; Herbst, R.; editores). Serie Correlación Geológica 14: 77-101. Tucumán.

Del Río, C.J. 2004. Tertiary marine molluscan assemblages of eastern Patagonia (Argentina): A biostratigraphic analysis. Journal of Paleontology 78: 1097-1122.

Del Río, C.J. 2007. El género Nodipecten Dall, 1898 (Bivalvia-Pectinidae) en el Neógeno de la Patagonia (Argentina). Ameghiniana 43: 745-756.

Del Río, C.J.; Martínez, S. 1998. Moluscos marinos miocenos de la Argentina y del Uruguay. Parte 1, Clase Bivalvia. Academia Nacional de Ciencias Exactas, Físicas y Naturales, Monografía 15: 48-83.

Del Río, C.J.; Martínez, S. 2006. The family Volutidae (Mollusca-Gastropoda) in the Tertiary of Patagonia (Argentina). Journal of Paleontology 80: 919-945.

Deshayes, G. 1832. Description des coquilles fósiles des environs de Paris. Muséum National d'Historie Naturelle. Archive 1: 147-290.

Deshayes, G. 1835. Histoire naturelle des animaux sans vertèbres, présentant les charactères généraux. Histoire des Mollusques, Paris, J.B. Baillière (Lamarck, $10^{\circ}$ ed.) 6 (4): 1-600. París.

De Vries, T.J.; Frassinetti, D. 2003. Range extensions and biogeographic implications of chilean Neogene mollusks found in Perú. Boletín del Museo Nacional de Historia Natural de Chile 52: 119-135.

Dieffenbach, E. 1843. Travels in New Zealand with contributions to the geography, geology, botany, and natural history of that country. John Murray, Chapter X: Fauna of New Zealand: 260. Londres.

Dolin, L. 1991. Cypraeoidea and Lamellarioidea (Mollusca: Gastropoda), from the Chipola Formation (Late Early Miocene) of Northwestern Florida. Tulane Studies in Geology and Paleontology 24 (1-2): 1-60.

Encinas, A.; Le Roux, J.P.; Buatois, L.A.; Nielsen, S.N.; Finger, K.L.; Fourtanier, E.; Lavenu, A. 2006. Nuevo esquema estratigráfico para los depósitos marinos miopliocenos del área de Navidad ( $\left.33^{\circ} 00^{\prime}-34^{\circ} 30^{\prime} \mathrm{S}\right)$, Chile central. Revista Geológica de Chile 33 (2): 221-246.

Encinas, A.; Finger, K.L.; Nielsen, S.N.; Lavenu, A.; Buatois, L.A.; Peterson, D.E.; Le Roux, J.P. 2008. Rapid and major coastal subsidence during the late Miocene in south-central Chile. Journal of South American Earth Sciences 25: 157-175.

Figueiras, A. 1985. Primera cita para la Argentina del género Cypraea Linné, 1758 (Mollusca: Gastropoda) y descripción de una nueva especie para la Formación Roca, Provincia de Río Negro, Argentina. Patagoniana 1: $1-6$.

Finger, K.L.; Nielsen, S.N.; De Vries, T.; Encinas, A.; Peterson, D.E. 2007. Paleontologic evidence for sedimentary displacement in Neogene forearc basins of central Chile. Palaios 22: 3-16.

Finlay, H. 1927. New specific names of Austral Mollusca. Transactions and Proceedings of the Royal Society of the New Zealand Institute 57: 488-533.

Finlay, H. 1930. Additions to the Recent Molluscan fauna of New Zealand. No. 3. Transactions and Proceedings of the New Zealand Institute 61: 67.

Fisher, P. 1880-87. Manuel de Conchyliologie et de Paléontologie conchiologique, ou Histoire Naturelle des Mollusques Vivants et Fossiles (Fisher, P.; editor). Paris.

Fleming, J. 1822. The philosophy of Zoology, or a general view of the sructure, functions and classifications of Animals (Constable, A.; editor): 618 p. Edinburgo.

Forbes, E. 1838. Malacología Monensis. A Catalogue of the mollusca inhabiting the Isle of Man and the neighboring sea: 63 p. Edinburgo.

Franchi, M.R.; Nullo, F.E.; Sepúlveda, E.; Uliana, M.A. 1984. Las sedimentitas terciarias. In Congreso Geológico Argentino, No. 9, Relatorio 1: 215-266. Río Negro.

Frassinetti, D.; Covacevich, V. 1984. Estudio del género Glycymeris Da Costa, 1778 en el Terciario de Chile con descripción de dos nuevas especies (Mollusca:Bivalvia). Boletín del Museo Nacional de Historia Natural de Chile 40: 107-133.

Frassinetti, D.; Covacevich, V. 1993. Bivalvos del Mioceno marino de Matanzas (Formación Navidad, Chile cen- 
tral). Boletín del Museo Nacional de Historia Natural de Chile 44: 73-97.

Frassinetti, D.; Covacevich, V. 1999. Invertebrados fósiles marinos de la Formación Guadal (Oligoceno SuperiorMioceno Inferior Inferior) en Pampa Castillo, Región de Aisén, Chile. Boletín del Servicio Nacional de Geología y Minería (Chile), Boletín 51: 1- 96.

Gardner, J. 1938. The Molluscan Fauna of the Alum Bluff Group of Florida. U.S. Geological Survey, Professional Paper 142-F: 251-435.

Gibson-Smith, J.; Gibson-Smith, W. 1988. Further notes on Eudolium (Galeodolium) subfasciatum. Tulane Studies in Geology and Paleontology $21(3,4): 119$.

Gray, J. 1847. A list of the genera of Recent Mollusca, their synonyma and types. Proceedings of the Zoological Society of London 14: 129-219.

Gray, J.E. 1850. Description of a new genus and several new species of terrestrial, fluviatile and marine Molluscous animals inhabiting New Zealand. Proceedings of the Zoological Society of London 17: 164-169.

Griffin, M.; Nielsen, S.N. 2008. A revision of the type specimens of Tertiary molluscs from Chile and Argentina described by d'Orbigny (1842), Sowerby (1846) and Hupé (1854). Journal of Systematic Paleontology 6 (3): 251-316.

Guppy, R. 1866. Jamaican Mollusca. The Quarterly Journal of Geological Society of London 22: 287.

Haller, M. 1978. Estratigrafía de la región al poniente de Puerto Madryn. In Congreso Geológico Argentino, No. 7, Actas 1: 285-297. Neuquén.

Haller, M.; Mendia, J. 1980. Las sedimentitas del ciclo Patagoniano en el litoral atlántico nordpatagónico. Coloquio ‘Ricardo Wichmann'. In Congreso Geológico Argentino, No. 8, Actas 3: 593-606. San Luis.

Herrmannsen, A.N. 1846. Indicis generum malacozoorum primordia. Nomina subgenerum, generum, familiarum, tribuum, ordinum, classium; adjectis auctoribus, temporibus, locis systematicis atque literariis, etymis, synonymis. Praetermittuntur Cirripedia, Tunicata et Rhizopoda 1: 637 p. Cassel. (Fischer).

Ihering, H. von. 1897. Os molluscos dos terrenos terciarios da Patagonia. Revista do Museu Paulista 2: 217-382.

Ihering, H. von. 1899. Die Conchylien der patagonischen Formation. Neues Jahrbuch für Mineralogie, Geologie und Paläontologie 2: 1-46.

Ihering, H. von. 1907. Les Mollusques fossiles du Tertiaire et du Crétacé supérieur de l'Argentine. Anales del Museo Nacional de Buenos Aires 14 (Serie 3, tomo 7): 1-611.

Kaaschieter, J.P. 1963. Geology of the Colorado Basin.
The Tulsa Geology Society Digest 31: 251-269.

Kaaschieter, J.P. 1965. Geología de la Cuenca del Colorado. Jornadas Geológicas Argentinas, No. 2, Actas 3: 251-271. Buenos Aires.

Lamarck, J.B. de. 1798. Tableau encyclopédique et méthodique des trois règnes de la nature. Vers testacés à coquilles bivalves, an VI. Editorial Agasse: 488 p. París.

Lamarck, J.B. de. 1809. Philosophie zoologique (Lamarck, J.B.; editor) 1: 1-422; 2:1-473. París.

Lamarck, J. de. 1816. Tableau Encyclopédique et Méthodique des Trois Règnes de la Nature (Veuve Hágase editor: 488 p. París.

Latreille, P. 1825. Familles naturelles du règne animal, exposées succinctement et dans un ordre analytique, avec 1'indication de leurs genres (Baillière, J.B.; editor): 570 p. Paris.

Linnaeus, K. von. 1758. Systema naturae per regna tria naturae. secundum classes, ordines, genera, species, cum characteribus, differentiis, syno-nymis, locis. Editorial Laurentius Salvias, Tomus I, Editio decima, reformata: 824 p. Stockholm.

Lizuain, A. 1983. Descripción geológica de la Hoja 38j, Salinas del Gualicho, Provincia de Río Negro. Boletín del Servicio Geológico Nacional de la República Argentina 195: 1-48.

Lizuain, A.; Sepúlveda, E. 1978. Geología del Gran Bajo del Gualicho (Provincia de Río Negro). In Congreso Geológico Argentino, No. 7, Actas 1: 407-422. Neuquén.

Lovén, S.L. 1847. Om tungans bevapning hos mollusker. Översigt af Kungliga Vetenskapsakademien Förhandlinger 4 (6): 175-199.

Malumián, N.; Náñez, C. 1998. El género Transversigerina y la edad de la transgresión patagoniana. In Congreso Latinoamericano de Geología, No. 10 y Congreso Nacional de Geología Económica, No. 6, Actas 1: 285-290. Buenos Aires.

Martínez, S.; del Río, C.J.; Reichler, V.A. 1998. Moluscos marinos miocenos de la Argentina y de Uruguay. Clase Gastrópoda. Monografía de la Academia Nacional de Ciencias Exactas, Físicas y Naturales 15: 26-47.

Martínez, S.; Del Río, C.J. 2002. Late Miocene molluscs from the southwestern Atlantic Ocean (Argentina and Uruguay): a palaeobiogeographic análisis. Palaeogeography, Palaeoclimatology, Palaeoecology 188: 167-187.

Martínez, S.A.; Reichler, V.A.; Mooi, R.S. 2005. A new species of Abertella (Echinoidea: Scutellina) from the Gran Bajo del Gualicho Formation (Late Early Miocene-Early Middle Miocene), Río Negro Province, Argentina. Journal of Paleontology 79: 1229-1233. 
Marwick, J. 1924a. An examination of some of the Tertiary Mollusca claimed to be common to Australia and New Zealand. Report of the Australian Association for the Advancement of Science 16: 316-331.

Marwick, J. 1924b. The Tertiary and Recent Naticidae and Naricidae of New Zealand. Transactions of the New Zealand Institute 55: 545-579.

Marwick, J. 1926. Molluscan Fauna of the Waiarekan Stage of the Oamaru Series. Transactions and Proceedings of the New Zealand Institute 56: 307-316.

Marwick, J. 1927. The Veneridae of New Zealand. Transactions of the New Zealand Institute 57: 567-635.

Monterosato, T.M. 1869-1923. Opera Omnia, 4 vols.: 1792 p. Milán.

Montfort, D. 1810. Conchyliologie systematique et classification methodique des coquilles: offrant leurs figures, leur arrangemet générique, leurs descriptions caractéristique, leur nomes; ansi que leur synonymie en plusieurs langues. Tome 2: Coquilles univalves, non cloisonnées (Schoell, F.; editor): 676 p. París.

Náñez, C. 1988. Foraminíferos y bioestratigrafía del Terciario medio de Santa Cruz oriental. Revista de la Asociación Geológica Argentina 43 (4): 493-517.

Neumayr, R. 1884. Zur morphologie des Bivalvenschlosses. Mathematischen und Naturforschungen Classe der Kaiserlichen Akademie der Wissenschaften in Wien. Sitzungsberichte 88: 385-419.

Nielsen, S. 2003. Die marinen Gastropoden (exclusive Heterostropha) aus dem Miozän von Zentralchile. Dissertation zur Erlangung des Doktorgrades der Naturwissenschaftenim Fachbereich Geowissenschaften der Universität Hamburg (Unpublished): 229 p.

Nielsen, S.N.; Glodny, J. 2006. The middle Miocene climate optimum in central and southern Chile: ${ }^{87} \mathrm{Sr} /{ }^{86} \mathrm{Sr}$ isotope stratigraphy on warm-water mollusks. In Congreso Geológico Chileno, No. 11, Actas 1: 93-96. Antofagasta.

Nielsen, S.N.; Frassinetti, D. 2007. The Neogene Volutidae (Gastropoda: Neogastropoda) from the Pacific Coast of Chile. Journal of Paleontology 81 (1): 82-102.

Núñez, E.; Bachmann, E.; Ravazzoli, I.; Britos, A.; Franchi, M.; Lizuain, A.; Sepulveda, E. 1975. Rasgos geológicos del sector oriental del macizo de Somuncurá, Provincia de Río Negro, República Argentina. In Congreso Iberoamericano de Geología Económica, No. 2, Actas 4: 247-266. Buenos Aires.

Olivera, A.; Camacho, H. 1990. Revisión del género Neoimbricaria Ihering, 1907 (Gastropoda, Neogastropoda) del Oligoceno de la Argentina. Anales de la Academia de Ciencias Exactas, Físicas y Naturales 42: 225-235.

Orbigny, A.d'. 1842. Voyage dans l'Amérique méridionale (le Brésil, la République Orientale de l'Uruguay, la République Argentine, la Patagonie, la République du Chili, la République de Bolivia, la République du Pérou) exécuté pendant les aneé es 1826, 1927, 1828, 1829, 1830, 1831, 1832 et 1833. 3 (4): Paleontologie). Chez P. Bertrand Libraire-Éditeur: 188 p. París.

Orbigny, A. d'. 1852. Stratigraphique universelle des animaux mollusques \& rayonnés faisant suitre au cours élémentaire de paléontologie et de géologie stratigraphique. Prodrome de Paléontologie 3: 189.

Ortmann, A.E. 1900. Synopsis of the collections of Invertebrate fossils made by Princeton Expedition to Southern Patagonia. American Journal of Sciences 10: 368-381.

Ortmann, A.E. 1902. Tertairy Invertebrates: In Reports of the Princeton University. Expedition to Patagonia 1896-1899 (Scott, W.B.; editor), volume 4, Paleontology I, Part 2. J. Pierpoint MorganPublishing Foundation: 45-332. Princeton, New Jersey.

Palazzesi, L.; Barreda, V. 2004. Primer registro palinológico de la Formación Puerto Madryn, Mioceno de la Provincia del Chubut, Argentina. Ameghiniana 41: 355-362.

Perry, G. 1811. Conchology, or the Natural History of Shells: containing a new arrangement of the genera and species, illustrated by coloured engravings executed from the natural specimens and including the latest discoveries (Miller, W.; editor): 4 p. Londres.

Petuch, E. 1988. Neogene History of Tropical American Mollusks. Biogeography and Evolutionary Patterns of Tropical Western Atlantic Mollusca. (Petuch, E.J.; editor): 217 p. Virginia.

Philippi, R.A. 1837. Pododesmus, ein neues Genus der Acephalen. Archiv für Naturgeschichte 3 (1): 385-387.

Philippi, R.A. 1887. Los fósiles Terciarios y Cuartarios de Chile. Editorial Brockhaus: 256 p. Leipzig.

Philippi, R. 1893. Descripción de algunos fósiles terciarios de la República Argentina. Museo Nacional de Chile, Tercera sección: Mineralogía, Geología y Paleontología. Anales 1: 1-16.

Quoy, J.; Gaimard, J. 1882-85. Voyages de découvertes de l'Astrolabe, sous le commandment de M.J. Dumont d'Urville (Tastu, J.; editor). Zoologie: Mollusca 2: 686 p. París.

Rafinesque, C. 1815. Analyse de la nature, ou tableau de l'Universe et des corps organisées (Barravecchia, J.; editor). Analyse Nature: 224 p. Palermo.

Reichler, V.A. 1989. Bioestratigrafía de los sedimentos marinos terciarios aflorantes en el área del cerro Fuerte Argentino, Provincia de Río Negro. Trabajo Final de 
Licenciatura (Inédito), Facultad de Ciencias Exactas y Naturales, Universidad de Buenos Aires: 126 p.

Reichler, V.A. 1995. Hercoglossa rionegrensis nov. sp. (Cephalopoda: Nautiloidea) en la Formación El Fuerte (Daniano), Provincia de Río Negro, República Argentina. Sociedad Científica Argentina, Anales 225: 121-128.

Reichler, V.A.; Camacho, H.H. 1991. Bioestratigrafía del Terciario marino entre los cerros Fuerte Argentino y Bandera, Provincia de Río Negro. Sociedad Científica Argentina, Anales 221: 19-34.

Rizzolo, E.J. 1967. Contribución a la estratigrafía de la parte oriental del Gran Bajo del Gualicho, Provincia de Río Negro. Trabajo Final de Licenciatura (Inédito), Facultad de Ciencias Exactas y Naturales, Universidad de Buenos Aires: 75 p. Buenos Aires.

Rizzolo, E.J. 1968. Description d’une faune d’ostracodes du Danien de l'Argentine (Gran Bajo del Gualicho). Coloquio de Micropaleontología Africano, No. 3, Actas 1: 603-621. El Cairo.

Röding, P. 1798. Museum Boltenianum sive catalogus cimeliorum e tribus regnis naturae quae olim collegerat Joa. Pars secunda continens sive Testacea univalvia, bivalvia \& multivalvia. Johan. Christi. Trappii: 199 p. Hamburgo.

Rossbach, T.; Carter, J. 1991. Molluscan Biostratigraphy of the Lower River Bend Formation at the Martin Marietta Quarry, New Bern, North Carolina. Journal of Paleontology 65 (1): 80-118.

Sacco, F. 1890. I Mollusquie dei terreni terziarii del Piemonte e della Liguria. Musei Zoologia e Anatomia Comparata, Realle Università de Torino, Bolletino 2 (41): 225-338.

Sacco, F. 1897. I Molluschi dei terreni terziarii del Piemonte e della Liguria. Museo Zoologia e Anatomia Comparata, Realle Università de Torino, Bolletino 12 (298): 99-102.

Scarabino, F.; Martínez, S.; Del Río, C.; Oleinik, A.E.; Camacho, H.H.; Zinsmeister, W.J. 2004. Two new species of Adelomelon Dall, 1906 (Gastropoda: Volutidae) from the Tertiary of Patagonia (Argentina). Journal of Paleontology 78: 914-919.

Scasso, R.A.; Del Río, C.J.; Macarthur, J.M.; Martínez, S.A. 1999. Edades ${ }^{87} \mathrm{Sr} /{ }^{86} \mathrm{Sr}$ para el Entrerriense (Mioceno) de península Valdés, Provincia del Chubut, Argentina. In Congreso Geológico Argentino, No. 14. Resúmenes, Actas 1: 73. Salta.

Scopoli, G.A. 1777. Introductio ad historiam naturalem, sistens genera lapidum, plantarum et animalium hactenus detecta, caracteribus essentialibus donata in tribus divisae, subinde ad leges naturae. Editor Wolfgand Gerle: 506 p. Praga.

Sepúlveda, E. 1983. Descripción geológica de la Hoja 38i, Gran Bajo del Gualicho, Provincia de Río Negro. Boletín del Servicio Geológico Nacional 194: 1-61.

Sepúlveda, E. 2003. Geología de las mesetas del Gualicho y los bajos que encierran, principalmente el Gran Bajo del Gualicho. In Bajo del Gualicho: Una planicie patagónica bajo el nivel del mar (Massera, R.F.; Guarido, J.C.; editores): 416 p. Río Negro.

Schmelz, G. 2001. The family Mitridae (Gastropoda) in the Lower Miocene Chipola Formation of northern Florida. The Nautilus 115 (2): 45-49.

Sowerby, R. 1846. Descriptions of Tertiary fossils shells from South America. In Geological Observations on South America Being the third part the geology of the voyage of the Beagle, under command of Capt. Fitzroy, R.N during the years 1832 to 1836 (Darwin, C.). Smith, Elder and Co.: 249-264. Londres.

Suárez, M.E.; Encinas, A.Y.; Ward, D. 2006. Early Miocene Elasmobranch Fauna from the Navidad Formation, Central Chile, South America. Cainozoic Research 4 (1-2): 3-18.

Suter, H. 1913. New species of Tertiary Mollusca. Transactions of the New Zealand Institute 45: 294-297.

Suter, H. 1917. Descriptions of new Tertiary Mollusca occurring in New Zealand, accompanied by a few notes on necessary changes in nomenclature (Part1). New Zealand Geological Survey, Paleontological Bulletin 5: 1-93.

Swainson, W. 1829. Zoological illustrations, or Original figures and descriptions of new rare, or otherwise interesting animals, selected chiefly principally from the classes of Ornithology, Entomology, and Conchology (Baldwin, Craddock, and Havell, R.; editors). Serie 2 (1-3), 136 pls. Londres.

Uliana, M.A. 1973. Geología de la región comprendida entre los ríos Colorado y Negro. Tesis Doctoral (Inédito), Facultad de Ciencias Naturales, Universidad Nacional de La Plata: 232 p.

Vokes, E.H. 1965. Cenozoic Muricidae from the Western Atlantic region. Part. II, Chicoreus sensu stricto and Chicoreus (Striatus). Tulane Studies in Geology and Paleontology 3 (4): 181-204.

Vokes, E.H. 1974. Notes on Chicoreus (Mollusca: Gastropoda) from the Cenozoic of the Western Atlantic region, with the description of new species. Tulane Studies in Geology and Paleontology 11 (2): 81-95.

Vokes, E.H. 1986. Notes on the fauna of the Chipola Formation. XXX. On the presence of Eudolium 
(Galeodolium) subfasciatum Sacco (Gastropoda: Tonnidae). Tulane Studies in Geology and Paleontology 19 (3-4): 177-180.

Wichmann, R. 1916. La constitución geológica del Territorio de Río Negro y la región vecina especialmente de la parte oriental entre el río Negro y Valcheta. Sociedad Argentina de Ciencias Naturales, Reunión Nacional de Ciencias Naturales, No. 1, 1: 88-107. Tucumán.

Wichmann, R. 1919. Contribución a la geología de la región comprendida entre el río Negro y el arroyo Valcheta, con una descripción petrográfica de las rocas eruptivas y metamórficas por Franco Pastore. Ministerio de Agricultura de Buenos Aires, Sección Geología, Mineralogía y Minería, Anales 12: 202-234.

Wichmann, R. 1927. Resultados de un viaje de estudios geológicos en los territorios del Río Negro y del Chubut. Publicación del Ministerio de Agricultura,
Dirección General de Minas, Geología e Hidrogeología de Buenos Aires 33: 1-31.

Woodring, W.P. 1928. Miocene Mollusks from Bowden Jamaica. Part. 2: Gastropods and discussion of results. Publication of the Carneige Institute of Washington 385: 1-564.

Woodring, W.P. 1970-82. Geology and paleontology of Canal Zone Adjoining parts of Panama. United States Geological Survey, Professional Paper 306 (A-F): 1-759.

Wright, J.D.; Miller, K.G.; Fairbanks, R.G. 1991. Evolution of modern deepwater circulation: evidence from the Late Miocene Southern Ocean. Paleoceanography 6: 275-290.

Zinsmeister, W.J.; Marshall, L.G.; Drake, R.E.; Curtis, G.H. 1981. First radioisotope (Potassium-Argon) age of marine Neogene Río Negro beds in northeastern Patagonia, Argentina. Science 212 (4493): 440.

Manuscrito recibido: noviembre 24, 2008; revisado/aceptado: septiembre 25, 2009. 


\section{APÉNDICE. PALEONTOLOGÍA}

Los repositorios y siglas de colección del material analizado pertenecen al laboratorio de Paleoinvertebrados del Museo Argentino de Ciencias Naturales Bernardino Rivadavia (MACN-Pi), Museo Paleontológico Bariloche (MPB) y Cátedra de Paleontología de la Universidad de Buenos Aires (CPBA). La clasificación utilizada para los bivalvos corresponde a la propuesta por Bieler y Mikkelsen (2006); para los gastrópodos se ha empleado la de Bouchet y Rocroi (2005). Todas las dimensiones están expresadas en milímetros. Las abreviaturas utilizadas son: $\mathrm{Al}=\mathrm{alto}$; L=largo; Lch=largo de charnela; Aap=ángulo apical; $\mathrm{An}=$ ancho; Do=diámetro del ombligo; $\mathrm{Au}=$ alto de la última vuelta; $\mathrm{Aa}=$ altura de abertura.

\section{DESCRIPCIONES SISTEMÁTICAS}

\author{
Phylum Mollusca Linnaeus, 1758 \\ Clase Bivalvia Linnaeus, 1758 \\ Subclase Pteriomorphia Beurlen, 1944 \\ Superfamilia Arcoidea Lamarck, 1809 \\ Familia Arcidae Lamarck, 1809 \\ Género Anadara Gray, 1847
}

Especie tipo: Arca antiquata Linnaeus, 1758 (por designación original). Reciente, Madagascar.

\section{Anadara australis sp. nov. \\ Lám. 1, Figs. 1-4}

Diagnosis: charnela delgada y recta, equivalente al $95 \%$ del largo total de la conchilla, inclinada posteriormente; área ligamentaria estrecha y elongada. Margen dorsoposterior alto, recto y largo, con leve inclinación distal; margen dorso-anterior cóncavo, expandido distalmente, formando un ángulo de $110^{\circ}$ en su unión con el margen ventral. Margen ventral posterior corto y vertical.

Etimología: por la latitud sur en que se encuentra.

Descripción: conchilla gruesa, inflada, subtrapezoidal, inequilateral. Umbón ancho, prosógiro a $1 / 4$ del extremo anterior. Área ligamentaria estrecha y larga, más ancha anteriormente. Adultos con tres surcos paralelos al margen externo, semejantes a chevrones incompletos; juveniles con surcos subhorizontales, inclinados posteriormente, subparalelos entre sí, divergentes respecto al umbón. Margen dorso-anterior levemente cóncavo, expandido distalmente, anguloso en su unión con el ventral $\left(110^{\circ}\right)$ anteriormente convexo, inclinado posteriormente, trun- cado en su unión con el margen posterior ventral que es corto, recto y vertical. Margen dorso-posterior alto y recto, con longitud equivalente al triple del margen anterior. Área posterior subauricular, marcada por un cambio en la convexidad de la conchilla y una disminución en el grosor de las costillas radiales. Charnela recta, delgada y larga, equivalente al 95\% del largo total, con moderada inclinación posterior. Dientes numerosos, cortos, subparalelos y subiguales, distalmente divergentes respecto al umbón. Ornamentación externa de 28-31 costillas radiales fuertes y redondeadas, más anchas y elevadas posteriormente, separadas por interespacios equivalentes a $1 \frac{1}{2}$ costilla, atravesadas por tres surcos comarginales profundos, regularmente espaciados. Margen ventral interno fuertemente crenulado.

Observaciones: Anadara lirata (Philippi, 1893; Del Río y Martínez, 1998; formaciones Puerto Madryn y Paraná (Argentina) y Formación Camacho (Uruguay)), posee mayor altura, menor longitud, margen dorso-anterior fuertemente inclinado, margen ventral posterior ampliamente redondeado, charnela más corta y área ligamentaria más ancha.

Anadara bravardi del Río (Del Río y Martínez, 1998); formaciones Puerto Madryn, Paraná y perforaciones 'entrerrienses' del Riachuelo (Argentina) presenta menor longitud, margen posterior más bajo, anterior más corto, umbón más anterior, menor cantidad de dientes, margen charnelar más corto y área ligamentaria más ancha.

Anadara plana del Río(Del Río, 1991; Del Ríoy Martínez, 1998; Formación Paraná) se distingue por su menor longitud, mayor altura, umbón más anterior, área ligamentaria más ancha, charnela más corta y arqueada y ornamentación con interespacios más anchos que las costillas.

Material y dimensiones: 6 valvas derechas, 6 izquierdas, dos unidas y numerosos fragmentos. Holotipo MACN-Pi 4729, $\mathrm{Al}=32, \mathrm{~L}=46$; Paratipo MACN-Pi 4731, $\mathrm{Al}=27$, $\mathrm{L}=39$; MACN-Pi 4730, Al=35, L=48; Lote MACN-Pi 4778; Lote MPB 3233-26.

Procedencia: Formación Gran Bajo del Gualicho, Miembro Saladar (sección inferior), Salinas del Gualicho.

\section{Superfamilia Ostreoidea Rafinesque, 1815 \\ Familia Ostreidae Rafinesque, 1815 Género Cubitostrea Sacco, 1897}

Especie tipo: Ostrea cubitus Deshayes, 1832 (por designación original). Eoceno, Francia. 


\section{Cubitostrea delrioi sp. nov. Lám. 1, Figs. 14-15}

Diagnosis: forma lanceolada-espatulada, expandida posteroventralmente. Valva izquierda con 35-40 pliegues radiales. Escultura xenomórfica de un surco cóncavo estrecho con bordes irregulares extendido desde el umbón hasta el extremo ventral. Inserción muscular ojival, en posición posteromediana, coincidiendo su margen ventral con el sector mediano de la expansión posteroventral.

Etimología: dedicado a la Dra. Claudia J. Del Río, investigadora de la fauna de moluscos marinos terciarios de Argentina.

Descripción: conchilla mediana, moderadamente inflada; forma lanceolada-espatulada con expansión posteroventral. Umbón puntiagudo y opistógiro. Valva izquierda con margen anterior amplio; posterior dorsalmente recto, ventralmente subcóncavo y subanguloso en su unión con el margen ventral, cuya convexidad varía en función de la amplitud posteroventral. Margen dorsal corto, con chomatas bien impresas anterior y dorsalmente, acuminado umbonalmente; área ligamentaria estrecha; resilífer triangular, moderadamente profundo. Superficie externa con sets escamosos finos y apretados; ornamentación de valva izquierda de 35-40 pliegues radiales agudos, separados por interespacios equivalentes a $1 / 2$ del ancho de cada uno. Escultura xenomórfica de surco cóncavo estrecho y agudo con bordes irregulares extendido desde el umbón hasta el margen ventral crenulado. Superficie interna lisa; inserción muscular ojival posteromediana, expandida anteroventralmente, cóncava anterodorsalmente, coincidiendo su margen ventral con el sector mediano de la expansión posteroventral. Músculo de Quenstedt dorsomediano.

Observaciones: Cubitostrea alvarezii (d'Orbigny, 1842; formaciones Puerto Madryn y Paraná) se diferencia por su forma subtriangular, valva izquierda con menor número de costillas radiales (22 a 26) e inserción muscular posterior de forma semicircular-subrectangular.

Material y dimensiones: 6 valvas izquierdas. Lote MACN-Pi 4790. Holotipo MACN-Pi 4788: $\mathrm{Al}=56, \mathrm{~L}=34$; Paratipo MACN-Pi 4789: $\mathrm{Al}=51, \mathrm{~L}=37$.

Procedencia: Formación Gran Bajo del Gualicho, Miembro Arriola (sección media). Salinas del Gualicho y afloramientos del camino de la Ruta Provincial No. 2.

\section{Superfamilia Pectinoidea Rafinesque, 1815 Familia Pectinidae Rafinesque, 1815 Género Zygochlamys Ihering, 1907}

Especie tipo: Pecten geminatus Sowerby, 1846 (por designación original). Eoceno tardío-Oligoceno temprano, Argentina.

\section{Zygochlamys rizzoloi sp. nov. Lám. 2, Figs. 1-6.}

Diagnosis: conchilla suborbicular. Ángulo que forma el margen posterior de la aurícula posterior de valva derecha con ligamento externo $=110^{\circ}$. Discos con 30-32 pliegues redondeados y bajos; aurícula posterior de valva derecha con 9-11 costillas muy delgadas, aurícula anterior de valva izquierda con 11-18 costillas muy delgadas.

Etimología: dedicado al Lic. E. J. Rizzolo.

Descripción: conchilla suborbicular, grande, inequilateral, opistoclina, levemente opistógira, con menor convexidad en la valva derecha que en la izquierda. Juveniles subtriangulares, más altos que largos, subequilaterales; adultos suborbiculares, equidimensionales, inequilaterales, marcadamente opistoclinos. Valva derecha con escotadura bisal profunda y fascíolo bisal ancho; ctenolio bien desarrollado, con 4 a 8 dientes activos en la escotadura bisal; aurícula anterior alargada dorsoventralmente, de mayor longitud que la posterior, equivalente al doble del largo de la misma; aurícula posterior con margen posterior recto, inclinado posteriormente, formando un ángulo de $110^{\circ}$ con el ligamento externo. Valva izquierda con seno bisal somero; aurícula anterior alargada dorsoventralmente, con margen anterior recto o levemente convexo, más larga que la posterior, equivalente casi al doble del largo de la misma; aurícula posterior con margen posterior recto, inclinado posteriormente. Resilífer triangulary profundo. Valva derecha con cruras auriculares marcadas, prominente dentículo anterior; dientes del resilífer y dientes dorsales destacados. Valva izquierda con diente supradorsal bien definido e infradorsal poco destacado. Escultura externa con 30-32 pliegues redondeados ornamentados por costillas radiales finas, cuyo crecimiento se produce por bifurcación en la valva derecha y por intercalación en la izquierda, separados por interespacios que aumentan el ancho hacia el margen ventral donde equivalen a $1 \frac{1}{2} \mathrm{el}$ ancho del pliegue, a su vez recorridos por 1-3 costillas delgadas radiales y numerosas y muy delgadas lamelas comarginales. Valva derecha con aurícula posterior con 9-11 costillas delgadas, escamosas, en ocasiones intercaladas con otras más finas y aurícula anterior con 5-7 costillas delgadas escamosas; valva izquierda con aurícula anterior con 11-18 costillas muy delgadas y aurícula posterior con 10-17 costillas muy delgadas. Microescultura 'shagreen' en ambas valvas (disco y aurículas). 
Observaciones: Zygochlamys actinodes (Sowerby, 1846; Martínez y Del Río, 2002; Griffin y Nielsen, 2008; Formación Puerto Madryn) es menos opistoclina, más opistógira, con seno bisal casi imperceptible. Valva derecha con pliegues y costillas primarias más altas y valva izquierda menos convexa, con costillas primarias más altas y angostas.

\begin{tabular}{lcc}
\hline \multicolumn{1}{c}{$\begin{array}{c}\text { Característica } \\
\text { morfológica }\end{array}$} & $\begin{array}{c}\text { Zygochlamys } \\
\text { rizzoloi sp. nov. actinodes (Sow.) }\end{array}$ & $\begin{array}{c}\text { Zygochlamys } \\
\text { No. costillas de aurícula anterior, VD }\end{array}$ \\
$5-7$ & $5-10$ \\
No. costillas de aurícula posterior, VD & $9-11$ & $10-20$ \\
No. costillas de aurícula anterior, VI & $11-18$ & $23-30$ \\
No. costillas de aurícula posterior, VI & $10-17$ & $15-25$ \\
No. de pliegues en el disco, VI & $26-29$ & $40-50$ \\
No. de pliegues en el disco, VD & $26-32$ & $40-50$ \\
Ángulo formado entre el margen & $110^{\circ}$ & $90^{\circ}$ \\
posterior de aurícula posterior de VD & & \\
y el ligamento externo & & \\
\hline
\end{tabular}

Material y dimensiones: 12 valvas izquierdas, 9 valvas derechas y numerosas valvas fragmentadas. Holotipo MACN-Pi 4794 (VD), Al=94, L=94, Lch=46, Aap=69; Paratipo MACN-Pi 4795 (VI), Al=89, L=88, Lch=43, Aap $=111^{\circ}$. Lote MACN-Pi 4796.

Procedencia: Formación Gran Bajo del Gualicho, Miembro Arriola (sección media). Salinas del Gualicho y afloramientos del camino de la Ruta Provincial No. 2.

\section{Familia Propeamussiidae Abbott, 1954 Género Amusium Röding, 1798}

Especie tipo: Amusium pleuronectes (Linnaeus, 1758) (subsecuente de Herrmannsen, 1846). Reciente, Pacífico occidental.

\section{Amusium rorii sp. nov.}

Lám. 2, Figs. 7-12

Diagnosis: margen posterior de aurícula anterior derecha suavemente redondeado. Interior de ambas valvas recorrido por 20-24 pares de costillas delgadas y redondeadas, muy destacadas ventralmente, donde se intercalan anterior y posteriormente dentro de cada par una tercera costilla que recorre sólo $1 / 4$ de la altura total.

Etimología: dedicado a mi hijo Rodrigo.

Descripción: conchilla mediana, muy delgada, equilateral, equiconvexa, casi plana, más alta que larga. Angulo umbonal $=110^{\circ}$. Margen dorsal auricular recto $(40 \%$ del largo total). Aurículas medianas, subiguales. Margen posterior de aurícula anterior derecha suavemente redondeado, con escotadura bisal relíctica. Margen posterior de aurícula posterior derecha recto, formando un ángulo de $120^{\circ}$ con el margen dorsal. Resilífer pequeño y triangular, poco profundo, más alto que largo. Cruras auriculares muy marcadas con dentículos destacados; dientes del resilífer y dorsales impresos. Escultura externa de disco y aurículas dada por delgadas líneas comarginales, destacadas hacia el margen ventral. Interior de ambas valvas recorrido por 20-24 pares de costillas delgadas y redondeadas, muy destacadas ventralmente en donde se intercalan anterior y posteriormente dentro de cada par una tercera costilla que recorre $1 / 4$ de la altura total. Interespacios entre pares de costillas $=1 \frac{1}{2}$ espacio entre costillas apareadas.

Observaciones: Amusium paris del Río (1992, Formación Puerto Madryn) es más orbicular, con mayor ángulo apical, margen dorsal más corto, margen anterior de aurícula derecha sigmoidal y mayor interespacio entre costillas apareadas.

Material y dimensiones: 5 valvas derechas, 2 valvas izquierdas fragmentadas (MACN-Pi 4793) y 2 fragmentos de discos. Lote MACN-Pi 4793. Holotipo MACNPi 4791: $\mathrm{Al}=29, \mathrm{~L}=28, \mathrm{Lch}=13$, Aap=120; Paratipo MACN-Pi 4792 (charnela framentada): $\mathrm{Al}=73, \mathrm{~L}=75$, Aap $=118^{\circ}$.

Procedencia: Formación Gran Bajo del Gualicho, Miembro Saladar (secciones inferior y superior). Afloramientos aledaños al camino de la Ruta Provincial No. 2, Salinas del Gualicho.

\section{Superfamilia Anomioidea Rafinesque, 1815 Familia Anomiidae Rafinesque, 1815 Género Pododesmus Philippi, 1837}

Especie tipo: Pododesmus rudis (Broderip, 1834) (Por monotipia). Reciente, desde Carolina del Sur (Estados Unidos) hasta el golfo de San Matías (Argentina).

\section{Subgénero Monia Gray, 1850}

Especie tipo: Anomia zelandica Gray, 1850 (en Dieffenbach, 1843). Plioceno temprano-Reciente, Nueva Zelanda.

\section{Pododesmus (Monia) atlantica sp. nov. Lám. 1, Figs. 5-6}

Diagnosis: tapón bisal oval, grande y calcificado; foramen muy pequeño, próximo al margen dorsal.

Etimología: de la transgresión atlántica que originó los depósitos que contienen la fauna. 
Descripción: valva derecha mediana, subcircular-piriforme, muy delgada, inequilateral, más alta que larga. Umbón diminuto. Región dorsal muy cóncava; tapón bisal oval, grande y calcificado; foramen ojival muy pequeño, proximal al tapón, con bordes elevados. Surcos de ligamento interno muy simple. Margen dorsal corto, levemente convexo; margen anterior proximalmente cóncavo, distalmente convexo, ligeramente expandido ventralmente; margen posterior recto e inclinado dorsalmente, convexo distalmente. Margen ventral liso y redondeado. Escultura externa de arrugas irregulares comarginales atravesadas por estrías radiales muy finas. Interior liso; impresión del músculo retractor del biso grande. Valva izquierda desconocida.

Observaciones: esta nueva especie es la primera representante del subgénero en Argentina. Pododesmus valchetanus Ihering, 1907, Pododesmus juliensis Ihering, 1907, Pododesmus paucisquamatus Ihering, Pododesmus papyraceus (Philippi, 1893; in Ihering, 1897) y Pododesmus camachoi del Río y Martínez, descritas para el Cenozoico patagónico se distinguen por sus valvas derechas muy gruesas, tapón bisal pequeño e impresión del músculo retractor del biso pequeño.

Pododesmus (Monia) zelandica (Gray; in Boreham, 1965, Mioceno tardío, Nueva Zelanda) se distingue por su escultura externa de costillas radiales altas, estrechas y regulares.

Material y dimensiones: 9 valvas derechas. Lote MACN-Pi 4799; Holotipo MACN-Pi 4797: Al=28, $\mathrm{L}=27$; Paratipo MACN-Pi 4798: $\mathrm{Al}=26, \mathrm{~L}=27$.

Procedencia: Formación Gran Bajo del Gualicho, Miembro Arriola (sección inferior), Salinas del Gualicho y afloramientos del camino de la Ruta Provincial No. 2.

\section{Subclase Heterodonta Neumayr, 1884 \\ Superfamilia Veneroidea Rafinesque, 1815 \\ Familia Veneridae Rafinesque, 1815 Género Tawera Marwick, 1927}

Especie tipo: Venus spissa Deshayes, 1835 (por designación original). Plioceno tardío-Reciente, Nueva Zelanda y Australia.

\section{Tawera canalei sp. nov. Lám. 1, Figs. 10-13}

Diagnosis: conchilla orbicular con área posterior deprimida; ángulo formado entre $2 \mathrm{a}$ y $2 \mathrm{~b}=80^{\circ}$; ornamentación de numerosas lamelas comarginales muy delgadas, más elevadas y menos espaciadas hacia el margen ventral.
Etimología: dedicado al Ing. Carlos Mario Canale. Descripción: conchilla orbicular, mediana a grande, equivalva, gruesa, moderadamente convexa, equidimensional. Margen dorsal arqueado, inclinado y truncado posteriormente; abruptamente truncado y vertical anteriormente. Margen ventral amplio y convexo. Área posterior deprimida, principalmente en el sector postero-ventral. Umbón pequeño, anguloso y prosógiro, a $1 / 4$ de distancia del margen dorsoanterior. Escudete largo y angosto; lúnula mediana, horizontal, recta, con surco lunular inciso. Dientes charnelares muy divergentes. Valva izquierda con 2 a robusto, subtriangular, paralelo al margen lunular; $2 \mathrm{~b}$ robusto, subtriangular, con surco longitudinal anterior, formando un ángulo de $80^{\circ}$ con 2 a y $4 \mathrm{~b}$ lanceolado, largo, curvado anteriormente, unido a la ninfa. Valva derecha con 3a subtriangular, subparalelo al margen lunular; 1 robusto, triangular y acanalado y $3 \mathrm{~b}$ triangular, elongado, acanalado, subparalelo a la ninfa. Ornamentación de lamelas comarginales muy delgadas, más elevadas y menos espaciadas hacia el margen ventral. Seno paleal corto, ascendente y agudo, con margen dorsal cóncavo y ventral convexo. Margen interno crenulado.

Observaciones: Tawera marshalli Marwick, 1927 (Nueva Zelanda, Mioceno temprano) posee menor tamaño, forma oval, ornamentación de costillas comarginales, 4 b separado por un surco de la ninfa, 3 b corto, 1 entero y 3 a lamelar. Material y dimensiones: 4 valvas izquierdas, 3 valvas derechas y 2 moldes articulados. Lote MACN-Pi 4726. Holotipo MACN-Pi 4721, Al=62, L=62; Paratipo MACNPi 4722, Al=40, L=41; Paratipo MPB 3224-26.

Procedencia: Formación Gran Bajo del Gualicho, Miembro Saladar (secciones inferior y superior), Salinas del Gualicho.

Género Dosinia Scopoli, 1777 Subgénero Dosinia Scopoli, 1777

Especie tipo: Chama dosin Anderson (=Venus concéntrica Born, 1778) (por designación original). Reciente, desde Antillas menores hasta Santa Catarina (Brasil).

\section{Dosinia (Dosinia) salarensis sp. nov.}

\section{Lám. 1, Figs. 7-9}

Diagnosis: margen ventral posterior recto y vertical. Lúnula fuertemente impresa, con marcada concavidad. Valva derecha con 3 a trapezoidal, biselado posteriormente, 1 triangular, bífido y $3 \mathrm{~b}$ triangular, paralelo a la ninfa, fusionado a 1 anteriormente.

Etimología: en alusión a la Gran Salina del Gualicho. 
Descripción: conchilla orbicular, mediana, gruesa, convexa, equivalva y equidimensional. Umbón pequeño, anguloso, a $1 \frac{1}{4}$ del margen anterior. Escudete no definido; lúnula mediana, cóncava, lanceolada, muy impresa, con surco profundo. Ninfas anchas. Margen dorsal subrecto, inclinado anteriormente; margen anterior expandido y redondeado; margen posterior convexo, inclinado ventralmente, truncado en su unión con el ventral que es recto y vertical en su cuarto posterior, luego redondeado. Valva derecha con 3 a trapezoidal, biselado posteriormente, 1 triangular, bífido y $3 \mathrm{~b}$ triangular, paralelo a la ninfa, fusionado anteriormente a 1 del cual se separa por un surco somero. Valva izquierda con 2 a subtriangular, elongado, biselado anteriormente, $2 \mathrm{~b}$ trapezoidal, $4 \mathrm{~b}$ lamelar, delgado, elongado, levemente curvado anteriormente y IIa pustular, bien marcado. Ornamentación externa de costillas comarginales, moderadamente anchas, irregulares, redondeadas y lisas, separadas por surcos delgados. Margen interno liso.

Observaciones: Dosinia (Dosinia) cuspidata del Río (Formación Puerto Madryn) presenta dientes laterales en valva derecha, 3 a delgado y corto, $3 b$ profundamente surcado, margen dorso-posterior más expandido, umbón más destacado y puntiagudo, lúnula menos cóncava y costillas comarginales más delgadas.

Dosinia (Dosinia) meridionalis (Ihering; in Del Río, 1994, formaciones San Julián, Monte León y Puerto Madryn) se distingue por presentar conchilla más delgada y menos inflada, ninfa más estrecha, umbón más pequeño y puntiagudo, lúnula menos cóncava, costillas comarginales más delgadas y regulares y dentición de valva derecha con 3 a delgado y corto, 1 entero y 3 b elongado, con surco profundo y de valva izquierda con 2a bífido.

Material y dimensiones: 6 valvas izquierdas, 7 valvas derechas y 6 moldes articulados. Holotipo MACN-Pi 4886, $\mathrm{Al}=56, \mathrm{~L}=51$ (reconstruido); Paratipo MACNPi 4887, $\mathrm{Al}=45, \mathrm{~L}=43$, Paratipo MPB 3221-26, $\mathrm{Al}=51$, $\mathrm{L}=48$; Lote MACN-Pi 4727; MPB 3218-26; MPB 316826; MPB 3221-26; MPB 3169-26; МРB3169-26; МРB 3223-26; 3169-26.

Procedencia: Formación Gran Bajo del Gualicho, Miembros Saladar (secciones inferior y superior) y Arriola (secciones inferior), Salinas del Gualicho.

Clase Gastropoda Cuvier, 1797 Subclase Caenogastropoda Cox, 1959

Superfamilia Cerithioidea Fleming, 1822

Familia Turritellidae Lovén, 1847 Género Spirocolpus Finlay, 1927
Especie tipo: Turritella waihaoensis Marwick, 1924a (por designación original). Eoceno Superior, Nueva Zelanda.

\section{'Spirocolpus' adapicis sp. nov. Lám. 4, Figs. 8-9}

Diagnosis: conchilla telescópica-biangulada; vueltas juveniles con $\mathrm{C}$ y $\mathrm{B}$ más destacadas que $\mathrm{A}$, luego $\mathrm{B}$ se debilita, $\mathrm{C}$ se mantiene de igual grosor y A se hace más fuerte hasta sobresalir en vueltas adultas. Interespacios $\mathrm{AB}=\mathrm{BC}$. Seno apertural profundo, con ápice situado sobre el cuarto adapical de la vuelta.

Etimología: del latín ad apical-is apex-apicis: hacia el ápice, en relación a la posición adapical de la carena más destacada.

Descripción: conchilla mediana, telescópica de espira elevada. Ángulo apical $=21^{\circ}$; ángulo pleural $=11^{\circ}$. Teleoconcha de hasta doce vueltas más anchas que altas separadas por suturas lineales profundas; vueltas juveniles convexas, luego planas y adultas telescópicas-bianguladas, con A más destacada. Base de la última vuelta plana, ángulo peribasal marcado por una carena espiral. Vueltas juveniles con C y B más fuerte que $\mathrm{A}$, luego $\mathrm{B}$ se debilita, $\mathrm{C}$ se mantiene de igual grosor y A se hace más fuerte hasta destacar en las últimas vueltas. Interespacios $\mathrm{AB}=\mathrm{BC}$. Escultura espiral secundaria variable.Abertura cuadrada, labio externo con seno profundo, simétrico, con ápice situado sobre el cuarto adapical.

Observaciones: en Argentina se conoce solo Spirocolpus pyramidesia (Ihering, 1907; Del Río y Martínez, 1998, Formación Puerto Madryn) que se distingue por sus carenas primarias con igual desarrollo e interespacios $\mathrm{BC}$ menores que AB.

Spirocolpus tophina (Marwick, 1926; Eoceno tardío-Oligoceno tardío, Nueva Zelanda) presenta una temprana aparición de A, aumento de C hasta formar conAlabiangularidad y disminución paulatina de $\mathrm{B}$ hasta ser obsoleta.

Material y dimensiones: 20 ejemplares y numerosos fragmentos. Holotipo MACN-Pi4806, $\mathrm{Al}=41, \mathrm{An}=0.8$; $\mathrm{Pa}-$ ratipo $\mathrm{MACN}-\mathrm{Pi} 4807, \mathrm{Al}=25$ (fragmentado), $\mathrm{An}=0.7$; lote MACN-Pi 4808; lote MACN-Pi 4850; MPB 3212-26.

Procedencia: Formación Gran Bajo del Gualicho, Miembro Saladar (secciones inferior y superior), Salinas del Gualicho.

\section{Género Torcula Gray, 1847}

Especie tipo: Turbo exoletus Linnaeus, 1758 (por designación original). Reciente, sudeste de Estados Unidos hasta Brasil. 


\section{Torcula magna sp. nov. Lám. 3, Figs. 4-6}

Diagnosis: conchilla grande; ontogenia caracterizada por a2 C1; C1 aparece en la cuarta vuelta y a2 en la octava; presencia de d en las vueltas juveniles y $\mathrm{D}$ en las adultas. Durante el desarrollo 'a' pasa a 'A' y 'C' pasa a 'c'. Inflexión del seno labial en D.

Etimología: del latín magnus-magna=grande, en alusión a su gran tamaño.

Descripción: conchilla grande, turriforme. Ángulo api$\mathrm{cal}=17^{\circ}$; ángulo pleural $=13^{\circ}-15^{\circ}$. Teleoconcha con veinte vueltas, más altas que anchas las juveniles y más anchas que altas las adultas, separadas por suturas lineales; vueltas neánicas planas, juveniles imbricadas, subcóncavas y adultas cóncavas, con A y $\mathrm{C}$ cinguladas. Ontogenia definida por: a2 $\mathrm{C} 1$; $\mathrm{C} 1$ aparece en la cuarta vuelta y a2 en la octava, a partir de la cual continúa el esquema: a $\mathrm{C}$ - a C d - a C d - a C d - A C d - A c D - A c D, con A en las últimas dos vueltas angulosa y saliente. Cinco últimas vueltas muy cinguladas. Abertura subcuadrada; inflexión del seno labial en D.

Observaciones: en Argentina se conoce 'Torcula' hauthali (Ihering, 1907; Del Río, 2004, Formación Chenque) que se distingue por la ausencia de D y presenta costillas espirales secundarias sobre la carena anterior y mitad posterior del espacio intercostal.

Torcula martinensis martinensis (Dall, 1892; Bowles, 1939, Oligoceno de Georgia y Florida) se distingue por su ontogenia A2 b3 C1 d, con temprana aparición de d.

Material y dimensiones: 21 ejemplares y numerosos fragmentos. Holotipo MACN-Pi 4851, Al=97, An=31; Paratipo MPB 3212-26, Al=72, An=19; MPB 3214-26, $\mathrm{Al}=73, \mathrm{An}=19$; $\mathrm{MPB} 3216-26, \mathrm{Al}=88, \mathrm{An}=34$; $\mathrm{MPB} 1286-$ 26, $\mathrm{Al}=87, \mathrm{An}=24$; MPB 3213-26, $\mathrm{Al}=97, \mathrm{An}=31$.

Procedencia: Formación Gran Bajo del Gualicho, Miembro Saladar (secciones inferior y superior), Salinas del Gualicho.

\section{Superfamilia Naticoidea Forbes, 1838 \\ Familia Naticidae Forbes, 1838 \\ Género Magnatica Marwick, 1924b}

Especie tipo: Polinices planispirus Suter, 1917 (por designación original). Oligoceno-Mioceno temprano, Nueva Zelanda.

Magnatica hansi sp. nov. Lám. 4, Figs. 5-7.
Diagnosis: labio interno recto, inclinado abaxialmente, formando un ángulo de $20^{\circ}$ respecto al eje axial, con profunda excavación abapical. Callo parietal subtriangular, extendido adapicalmente, engrosado abapicalmente formando un borde bajo y redondeado.

Etimología: dedicado al Lic. Juan José Reichler.

Descripción: conchilla mediana, oval-globosa, gruesa, umbilicada y de espira baja. Teleoconcha con cuatro vueltas plano-convexas separadas por suturas profundas; última vuelta convexa, globosa, con líneas prosoclinas destacadas. Abertura grande, semilunar; labio interno recto, inclinado abaxialmente, formando un ángulo de $20^{\circ}$ respecto al eje axial, con profunda excavación abapical. Callo parietal fuerte, moderadamente desarrollado, extendido adapicalmente con forma subtriangular, engrosado abapicalmente formando un borde bajo y redondeado. Ombligo moderado-pequeño, en ocasiones parcialmente cubierto por el callo, con borde funicular muy débil. Labio externo afilado, algo sinuoso y prosoclino, formando un ángulo de $28^{\circ} \mathrm{con}$ el eje axial.

Observaciones: Magnatica? chiloensis (Philippi, 1887; Nielsen, 2003, Mioceno, sur de Chile) presenta menor diámetro de última vuelta, callo parietal menos expandido adapicalmente y labio interno no excavado, con menor engrosamiento abapical.

Magnatica subsolida (d'Orbigny, 1852; Nielsen, 2003, Formación Navidad, Chile central) se distingue por su espira más baja, vueltas más convexas, suturas más impresas, callo parietal menos expandido y ausencia de excavación abapical en labio interno.

Magnatica planispira (Suter, 1917; Beu y Maxwell, 1990, Oligoceno-Mioceno temprano, Nueva Zelanda) posee menor desarrollo del callo parietal, abertura de mayor diámetro y labio interno recto.

Material y dimensiones: 28 ejemplares. Holotipo MACN-Pi 4812, Al=34, An=26=27; Paratipo MACN-Pi 4813, $\mathrm{Al}=34, \mathrm{An}=24$; $\mathrm{MPB} 3280-26, \mathrm{Al}=22, \mathrm{An}=17$; $\mathrm{MPB}$ 3281-26, Al=18, An=17; MPB lote 3248-26.

Procedencia: Formación Gran Bajo del Gualicho, Miembro Saladar (secciones inferior y media), Salinas del Gualicho.

\section{Superfamilia Tonnoidea Suter, 1913 \\ Familia Tonnidae Suter, 1913 \\ Género Eudolium Dall, 1889}

Especie tipo: Dolium crosseanum Monterosato, 1869 (por monotipia). Reciente; Océano Atlántico occidental. 


\section{Eudolium lissiei sp.nov. Lám. 3, Figs 7-11}

Diagnosis: plataformas con 22 nódulos axiales agudos; última vuelta con 5 cordones primarios espirales, el primero adapical fuertemente noduloso, los restantes poco nodulosos, entre los que se intercalan un cordón secundario y dos o más terciarios lisos.

Etimología: dedicado a mi hija Elisabeth.

Descripción: conchilla baja, pequeña-mediana, delgada y escalonada, globosa adapicalmente. Teleoconcha de 4 vueltas convexas, separadas por suturas lineares profundas; última vuelta globosa y expandida. Plataformas suturales destacadas y angulosas, recorridas por 22 nódulos axiales agudos periféricos. Última vuelta con 5 cordones primarios espirales, el primero adapical fuertemente noduloso, los restantes poco nodulosos, separados por interespacios cóncavos anchos, entre los que se intercalan un cordón espiral secundario liso y 2-6 terciarios. Abertura elongada, con altura equivalente al $83 \%$ de la última vuelta. Área parietal lisa; columela levemente cóncava, canal sifonal corto y recto; labio externo reflejado.

Observaciones: Eudolium aoteanum Beu(Beuy Maxwell, 1990; Mioceno temprano, Nueva Zelanda y Australia) posee espira más alta, plataformas menos detacadas y nodosidades poco marcadas, subiguales en todos los cordones espirales.

Eudolium subfasciatum (Sacco, 1890; Vokes, 1986; Gibson-Smith y Gibson-Smith, 1988, Mioceno temprano alto, Venezuela (Formación Cantaure) y Florida (Formación Chipola)) presenta espira más elevada, plataformas menos destacadas, última vuelta con nódulos poco destacados y mayor número de cordones primarios espirales.

Material y dimensiones: 4 ejemplares. Holotipo MPB 3952-26, $\mathrm{Al}=52, \mathrm{An}=34, \mathrm{Au}=48, \mathrm{Aa}=40$; Paratipo $\mathrm{MACN}$ $\mathrm{Pi} 4816, \mathrm{Al}=27, \mathrm{An}=23, \mathrm{Au}=24, \mathrm{Aa}=21$; $\mathrm{MACN}-\mathrm{Pi} 4817$, $\mathrm{Al}=32, \mathrm{An}=24, \mathrm{Au}=28, \mathrm{Aa}=23$; MACN-Pi 4815.

Procedencia: Formación Gran Bajo del Gualicho, Miembro Saladar (seccion inferior), Salinas del Gualicho.

\section{Familia Cassidae Latreille, 1825 Género Sconsia Gray, 1847}

Especie tipo: Cassidaria striata Lamarck, 1816 (por designación original). Reciente; sudeste de Estados Unidos hasta Brasil.

Sconsia magdai sp. nov. Lám. 3, Figs. 1-3
Diagnosis: última vuelta globosa, muy expandida adapicalmente, con várice axial fuerte recorrida por dos surcos longitudinales. Labio externo fuertemente engrosado y reflejado, formando un ángulo de $90^{\circ}$ entre el margen adapical y el eje axial.

Etimología: dedicado a la Prof. Magda A. Pauli.

Descripción: conchilla mediana, baja, gruesa y globosa; ápice agudo. Teleoconcha con 5 vueltas poco convexas, separadas por suturas lineares profundas, subcanaliculadas, esculturadas por cordones espirales bajos y lisos (2 por $\mathrm{mm}$ ). Última vuelta globosa, muy expandida adapicalmente, con plataforma poco marcada y fuerte várice axial, angulosa y engrosada adapicalmente, ubicada especular y simétricamente respecto al labro, recorrida longitudinalmente por dos surcos profundos. Abertura elongada ( $90 \%$ de la altura de la última vuelta), escotada adapicalmente; labio externo fuertemente engrosado, poco reflejado, recorrido internamente por numerosos dientes transversales, formando un ángulo de $90^{\circ}$ entre el margen adapical y el eje axial; labio interno con gruesa callosidad, moderadamente expandida, con tres pliegues columelares débiles, ubicados en el sector basal. Canal sifonal anterior corto, oblicuo, poco retorcido, con fascíola sifonal moderadamente desarrollada, surcada por dos estrías transversales.

Observaciones: Sconsia magdai sp. nov. constituye la primera mención válida del género para Argentina. En este país se había citado la presencia de Sconsia en la Formación Monte León. La especie, originalmente descrita como Dolium ovulum (Ortmann, 1900), fue ubicada como Sconsia por Ihering en el texto (Sconsia ovulum Ortmann; Ihering, 1907), mientras que por error en la lámina se citó como Cominella (Cominella ovulum Ortmann; Ihering, 1907, lám. 6, Figs. 36 a-b). Posteriormente, fue incluida dentro del género Semicassis Mörch (Semicassis ovulum (Ortmann); Frassinetti y Covacevich, 1999, Formación Guadal, Chile). Al revisar el material ilustrado por Ihering se ha notado la ausencia del fuerte repliegue del canal anterior que otorga la presencia de un falso ombligo característico de Semicassis; por otra parte, la presencia de escultura axial, ausencia de callo y labio externo no engrosado ni reflejado, interiormente surcado por estrías muy finas y paralelas apartan la especie ovulum de la diagnosis de Sconsia.

Sconsia montisnigri (como Cassidaria (Galeodea) montisnigri, Frenguelli, Formación Chenque) carece de várice axial, posee menor angulación entre el margen adapical y el eje axial, labio externo internamente liso, dos pliegues columelares y vueltas esculturadas por cordones espirales más delgados, de grosor equivalente a los interespacios. 
Sconsia laevigata sublaevigata (Guppy, 1866; Woodring, 1928, Formación Gatun, Canal de Panamá y Caribe) presenta espira más elevada, última vuelta con menor convexidad adapical y labio externo más angosto, menos reflejado, que forma un ángulo agudo entre el margen adapical y el eje axial.

Material y dimensiones: 10 ejemplares. Holotipo MPB 3201-26, $\mathrm{Al}=56, \mathrm{An}=39$; Paratipo MPB 3202-26, $\mathrm{Al}=54$, $\mathrm{An}=44$; MPB 3191-26; MPB 3211-26; MPB 3293-26; MPB 3215-26; MPB 3956-26: MPB 3957-26. MACN-Pi 4818. Procedencia: Formación Gran Bajo del Gualicho, Miembro Saladar (sección inferior), Salinas del Gualicho.

\section{Superfamilia Muricoidea Rafinesque, 1815 Familia Muricidae Rafinesque, 1815 Género Chicoreus Montfort, 1810 Subgénero Chicoreus Montfort, 1810}

Especie tipo: Murex ramosus Linnaeus, 1758 (por designación original). Reciente, Océano Indo-Pacífico.

\section{Chicoreus (Chicoreus) guadalupei sp. nov. Lám. 4, Figs. 13-15}

Diagnosis: escultura axial con 11 nódulos espinosos, alargados abapicalmente; última vuelta con 3 várices axiales gruesas y espinosas con intercalación de 2 nódulos espinosos. Espina apertural forma un ángulo de $50^{\circ} \mathrm{en} \mathrm{su}$ proyección respecto al eje axial.

Etimología: dedicado a mi hija Guadalupe.

Descripción: conchilla mediana, de espira mediana a baja. Teleoconcha de 6 vueltas convexas con plataformas destacadas separadas por suturas lineares profundas. Última vuelta dilatada y globosa adapicalmente. Escultura espiral constituida en las dos primeras vueltas por 4 carenas, en las siguientes tres vueltas por 6 carenas y última vuelta con 12 carenas principales altas, lisas y redondeadas, con 1 secundaria y 2 o 3 terciarias intercaladas entre cada par de primarias; interespacios cóncavos. Canal sifonal con 5 espiras adapicales. Escultura axial de 11 nódulos espinosos periféricos, alargados abapicalmente; última vuelta con 3 várices axiales gruesas con espinas adapicales largas y puntiagudas, curvadas adaperturalmente, entre las cuales se intercalan periféricamente 2 nódulos espinosos. La última várice, que es la más gruesa y contornea la abertura por el lado externo, se prolonga hacia el tope del canal sifonal posterior, constituyendo una espina periférica fuerte, hueca y abierta al frente que se dirige hacia arriba, formando un ángulo de $50^{\circ}$ en su proyección respecto al eje axial. Abertura oval-redondeada; labio interno liso y estrecho, fusionado al externo posteriormente y libre anteriormente; labro rugoso interior y exteriormente, ligeramente proyectado frente a la extremidad de la várice, subcóncavo adapicalmente. Canal sifonal corto, arqueado e inclinado siniestralmente.

Observaciones: Chicoreus (Chicoreus) dujuardinoides (Vokes, 1965, Formación Chipola, Florida) presenta espira más elevada, plataformas no destacadas y espinas poco desarrolladas.

Chicoreus (Chicoreus) elusivus Vokes, 1974 (Formación Chipola, Florida) posee espira más alta, ornamentación espiral más fuerte y espinas de várice labral más largas y finas.

Material y dimensiones: 2 ejemplares. Holotipo MACNPi 4820, $\mathrm{Al}=47, \mathrm{An}=34, \mathrm{Au}=41, \mathrm{Aa}=35$; Paratipo $\mathrm{MACN}-$ Pi 4821, $\mathrm{Al}=49, \mathrm{An}=43, \mathrm{Au}=32, \mathrm{Aa}=21$.

Procedencia: Formación Gran Bajo del Gualicho, Miembro Saladar (sección inferior), Salinas del Gualicho.

\section{Familia Mitridae Swainson, 1829 Género Mitra Lamarck, 1798}

Especie tipo: Voluta mitra Linnaeus, 1758 (por designación original). Reciente, Océano Indo-Pacífico e Islas Galápagos.

\section{Subgénero Fusimitra Conrad, 1855}

Especie tipo: Mitra millingtoni Conrad, 1855 (por designación original). Eoceno medio, Jackson, Mississippi.

\section{Mitra (Fusimitra) carlosi sp. nov. Lám. 3, Figs. 12-14}

Diagnosis: conchilla telescópica; última vuelta con altura equivalente a $2 / 3$ partes de la altura total. Columela excavada posteriormente; abertura con labro anteriormente recto e inclinado hacia la escotadura sifonal, posteriormente subcóncavo hasta su unión con el cuerpo de la espira. Punto de inflexión entre el margen subcóncavo y el recto $\mathrm{a}^{2 / 7}$ de distancia del canal anterior.

Etimología: dedicado al Ing. Carlos Mario Canale. Descripción: conchilla mediana, sólida, fusiforme, alta y telescópica. Teleoconcha con 4 vueltas altas y planas, subconvexas abaxialmente. Suturas lineales impresas. Escultura de carenas espirales finas, con interespacios equivalentes, desarrolladas desde las primeras vueltas hasta la mitad de la penúltima vuelta. Última vuelta lisa ( $2 / 3$ partes de la altura total), subconvexa, con escotadura anterior cóncava. Abertura alta $(65 \%$ de la altura de la 
última vuelta), estrecha, con márgenes subparalelos; labro delgado, anteriormente recto e inclinado hacia la escotadura sifonal, posteriormente subcóncavo hasta su unión con el cuerpo de la espira donde una convexidad delimita el canal posterior. Punto de inflexión entre el margen cóncavo y el recto a $2 / 7$ del canal anterior. Columela sigmoidal, excavada posteriormente, con tres pliegues subparalelos (par posterior más fuerte y separado).

Observaciones: Mitra (Fusimitra) calhounensis Schmelz, 2001 (Formación Chipola, Florida) posee vueltas más bajas, columela no excavada y labro posteriormente recto. Material y dimensiones: 1 ejemplar. Holotipo MACN-Pi 4824, $\mathrm{Al}=66, \mathrm{An}=19, \mathrm{Au}=46, \mathrm{Aa}=32$.

Procedencia: Formación Gran Bajo del Gualicho, Miembro Saladar (seccion inferior), Salinas del Gualicho.

\section{Género Austroimbricaria Olivera y Camacho, 1990}

Especie tipo: Marginella quemadensis Ihering, 1897 (por designación original). Mioceno, Provincia de Santa Cruz, Argentina.

\section{Austroimbricaria brugnii sp. nov. Lám. 4, Figs. 10-12}

Diagnosis: labro recto, paralelo al eje axial formando un ángulo de $90^{\circ}$ con la proyección de la sutura de la última vuelta. Columela con 4 pliegues, posterior y anteriormente apareados, con sendas inclinaciones de $55^{\circ}$ y $38^{\circ}$ respecto al eje axial.

Etimología: dedicado a la Prof. Norma Brugni.

Descripción: conchilla muy baja, pequeña, cónica y ápice puntiagudo. Teleoconcha con 3 vueltas lisas separadas por suturas obsoletas. Abertura alta, equivalente a toda la última vuelta; labro recto, paralelo al eje axial, formando un ángulo de $90^{\circ}$ con la proyección de la sutura de la última vuelta, levemente engrosado marginalmente. Surco sifonal posterior marcado en forma de ranura; escotadura sifonal anterior poco definida, con fascíola destacada. Columela con 4 pliegues fuertes, posterior y anteriormente apareados con sendas inclinaciones de $55^{\circ}$ y $38^{\circ}$ respecto al eje axial.

Observaciones: Austroimbricaria es un género endémico de la Patagonia argentina que hasta el momento había sido citado sólo para la Formación Monte León (Olivera y Camacho, 1990). El hallazgo del mismo en las sedimentitas del Miembro Saladar nov. amplía su distribución geográfica.

Austroimbricaria quemadensis (Ihering, 1897) presenta espira más alta, suturas deprimidas, escotadura sifonal anterior más marcada, canal sifonal posterior obsoleto, labro anguloso adapicalmente y pliegues columelares subperpendiculares al eje axial.

Austroimbricaria gracilior (Ihering, 1897) posee espira más elevada, escotadura sifonal anterior más pronunciada y columela con tres pliegues posteriores paralelos (los dos superiores de mayor longitud) y un cuarto pliegue anterior inclinado abapicalmente.

Material y dimensiones: 4 ejemplares. Holotipo MACNPi 4832, $\mathrm{Al}=19, \mathrm{An}=11, \mathrm{Au}=18$; Paratipo MACN-Pi 4833, $\mathrm{Al}=20, \mathrm{An}=11, \mathrm{Au}=18 ; \mathrm{MACN} \mathrm{P}-\mathrm{i} 4825, \mathrm{Al}=17, \mathrm{An}=8$, $\mathrm{Au}=10$; MACN-Pi 4826, $\mathrm{Al}=15, \mathrm{An}=8, \mathrm{Au}=13$; $\mathrm{MPB}$ 3229-26, $\mathrm{Al}=18, \mathrm{An}=9, \mathrm{Au}=16$.

Procedencia: Formación Gran Bajo del Gualicho, Miembro Saladar (seccion inferior), Salinas del Gualicho.

\section{Superfamilia Buccinoidea Rafinesque, 1815 Familia Buccinidae Rafinesque, 1815 Género Penion Fisher, 1884}

Especie tipo: Fusus dilatatus Quoy y Gaimard, 1883 (por designación original). Reciente, Nueva Zelanda.

\section{Penion patagonensis sp. nov. Lám. 4, Figs. 1-4}

Diagnosis: última vuelta con 7 nódulos axiales periféricos gruesos y puntiagudos; abertura triangular, labro con margen adapical cóncavo que forma un ángulo de $80^{\circ}$ con el abapical que es posteriormente recto y anteriormente cóncavo. Canal sifonal sigmoidal, con marcada curvatura anterior.

Etimología: en alusión a su procedencia patagónica. Descripción: conchilla grande, fusiforme, alta y gradada; ángulo espiral $=40^{\circ}$. Teleoconcha de 4-5 vueltas con 20-22 estrías espirales y 9 nódulos axiales abapicales, separadas por suturas lineares irregulares, moderadamente profundas; plataformas plano-cóncavas, muy inclinadas. Última vuelta alta $(2 / 3$ del alto total), con 37 estrías espirales regularmente distribuidas desde la sutura hasta el comienzo del canal sifonal, a partir del cual se desarrollan 11 carenas primarias anchas y redondeadas, surcadas ab y adapicalmente por delgadas carenas secundarias, separadas por interespacios lineares, estrechos y profundos. Escultura axial dada por 7 nódulos gruesos y puntiagudos, ubicados periféricamente en el sector mediano de la vuelta, elongados abapicalmente, separados por interespacios equivalentes a $1 \frac{1}{2}$ el ancho de cada nódulo. Abertura triangular, labio interno liso, con fina callosidad; labro delgado 
con margen adapical cóncavo que forma un ángulo de $80^{\circ}$ con el abapical que es posteriormente recto y anteriormente cóncavo. Columela muy excavada adapicalmente; canal sifonal largo, sigmoidal, con marcada curvatura anterior.

Observaciones: en Argentina hasta el momento el género estaba representado por Penion subrectus (Ihering, 1899, Formación Monte León). Esta especie fue redescrita por Ortmann (1902) y colocada bajo sinonimia de la especie chilena domeykoana (Philippi), la que a su vez fue ubicada posteriormente por Ihering (1907) en sinonimia de subrectus. Al revisar el material de Ihering se han observado diferencias en la espira, abertura y escultura respecto a domeykoana Philippi; mientras que se han encontrado analogías entre la especie de Ihering y la descripción de Ortmann, por lo que se considera que siguen siendo válidas las especies originales (subrectus Ihering para Argentina y domeykoana Philippi para Chile).P. subrectus presenta plataformas más anchas, última vuelta con 11 nódulos más bajos y más alargados, canal sifonal recto y abertura más angosta, con labro convexo mientras que P. domeykoana (Nielsen, 2003, Formación Navidad, Chile) posee espira más baja, plataformas más anchas y menos inclinadas, nódulos axiales más juntos y menos destacados, canal sifonal levemente curvado o recto y labro con margen adapical convexo.

Penion oncodes (Philippi, 1887; Nielsen, 2003, Formación Navidad, Chile) se distingue por sus vueltas más altas, plataformas más inclinadas, nódulos poco destacados, canal sifonal recto y labro convexo.

Penion subregularis (d'Orbigny, 1852; Nielsen, 2003, Formación Navidad, Chile) presenta plataformas más anchas y menos inclinadas, nódulos poco destacados, canal sifonal recto y abertura con margen labral adapical convexo.

Penion marwicki (Finlay, 1930; Beu y Maxwell, 1990, Mioceno temprano, Nueva Zelanda) posee espira más baja, plataformas más destacadas, escultura axial de costillas levemente nodulosas y abertura oval.

Material y dimensiones: 4 ejemplares. Holotipo MACN-Pi 4834, $\mathrm{Al}=64, \mathrm{Au}=44, \mathrm{An}=39$; Paratipo $\mathrm{MACN}$ $\mathrm{P}$-i 4835, $\mathrm{Al}=52, \mathrm{Au}=37, \mathrm{An}=27$; MACN P-i 4836; $\mathrm{MPB}$ 3952-26, $\mathrm{Al}=37, \mathrm{Au}=26, \mathrm{An}=22$.

Procedencia: Formación Gran Bajo del Gualicho, Miembro Saladar (sección inferior), Salinas del Gualicho.

\section{Superfamilia Conoidea Fleming, 1822 \\ Familia Turridae H. Adams y A. Adams, 1853 \\ Género Polystira Woodring, 1928}

Especie tipo: Pleurotoma albida Perry, 1811 (por designación original). Reciente, Estados Unidos e Indias Occidentales.

\section{Polystira cingula sp. nov. Lám. 4, Figs. 16-17}

Diagnosis: escultura caracterizada por una fuerte y angulosa carena espiral periférica cingulada y dos carenas espirales primarias, con estrías espirales secundarias intercaladas.

Etimología: del latín cingula-cingulae (=cincha) en alusión al cíngulo periférico que ornamenta las vueltas.

Descripción: conchilla alta, pequeña a mediana, fusiforme. Teleoconcha con 6 vueltas cóncavas, muy angulosas, plataformas empinadas y suturas obsoletas. Cada vuelta presenta una carena espiral abapical fuerte y angulosa, periféricamente cingulada y dos carenas espirales primarias, redondeadas y destacadas, entre las que se intercalan estrías espirales secundarias paralelas. Líneas opistoclinas axiales leves. Última vuelta con fuerte angulación peribasal, excavada abapicalmente, con escultura semejante al resto de las vueltas más una carena periférica basal que delimita el área columelar. Columela lisa, larga y recta. Abertura piriforme, fragmentada en su sector anterior; labro delgado, levemente crenulado interiormente, con seno anal somero en forma de 'V'.

Observaciones: en Argentina Polystira ha sido citado como integrante de la fauna de la Formación Puerto Madryn (Brunet, 1995; Martínez et al., 1998) sin asignación específica debido a su pobre preservación.

Polystira tenagos (Gardner, 1938; Woodring, 1970, Mioceno temprano tardío, México y Mioceno medio, Panamá), carece de cíngulos periféricos, posee plataformas menos destacadas y escultura espiral columelar.

Material y dimensiones: 5 ejemplares. Holotipo MACN- Pi 4837, Al=27, An=11, $\mathrm{Au}=16$; Paratipo MACN-Pi 4838, Al=30, An=11, Au=18; Lote MACNPi 4839; MPB 3244-26.

Procedencia: Formación Gran Bajo del Gualicho, Miembro Saladar (sección inferior), Salinas del Gualicho. 
LÁMINAS 1-4 


\section{LÁMINA 1}

Figuras 1-4: Anadara australis sp. nov.

1-2: Valva derecha, vistas exterior e interior (x 1). Holotipo, MACN-Pi 4729.

3-4: Valva izquierda, vistas exterior e interior (x 1). Paratipo MACN-Pi 4731.

Figuras 5-6: Pododesmus (Monia) atlantica sp. nov. Vistas exterior e interior de valva derecha (x 1). Holotipo, MACN -Pi 4797.

Figuras 7-9: Dosinia (Dosinia) salarensis sp. nov.

7-8: Vistas interior y exterior de valva izquierda (x 1). Holotipo, MACN-Pi 4886.

9: $\quad$ Vista interior de valva derecha (x 1). Paratipo, MPB 3221-26.

Figuras 10-13: Tawera canalei $\mathrm{sp}$. nov.

10-11: Vistas exteriores de valvas derecha e izquierda (x 1). Paratipo, MPB 3224-26.

12-13: Vistas interiores de valvas izquierda y derecha (x 1). Holotipo, MACN-Pi 4721.

Figuras 14-15: Cubitostrea delrioi sp. nov.

Vistas interior y exterior de valva izquierda (x 1).

Holotipo, MACN-Pi 4788. 

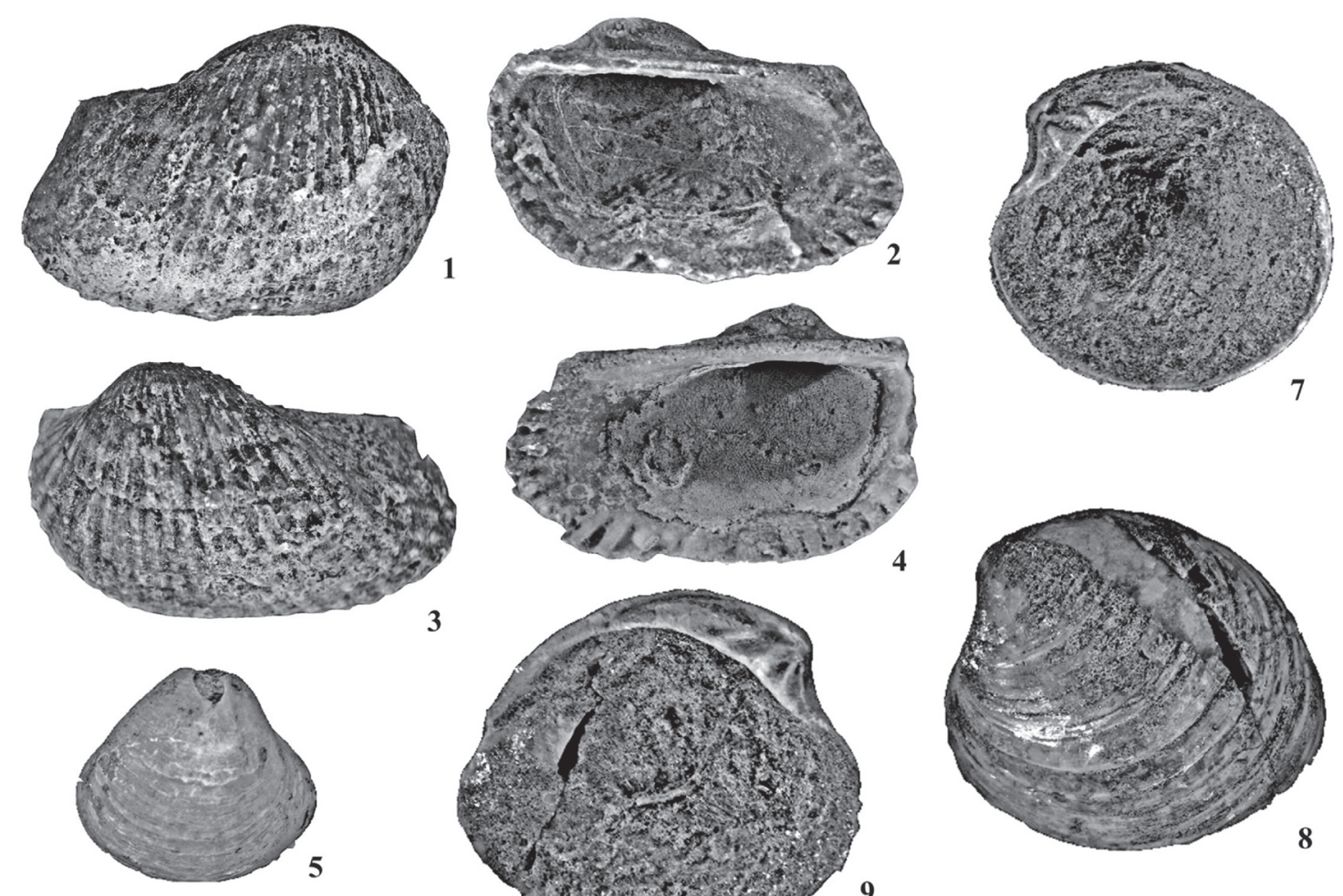

3
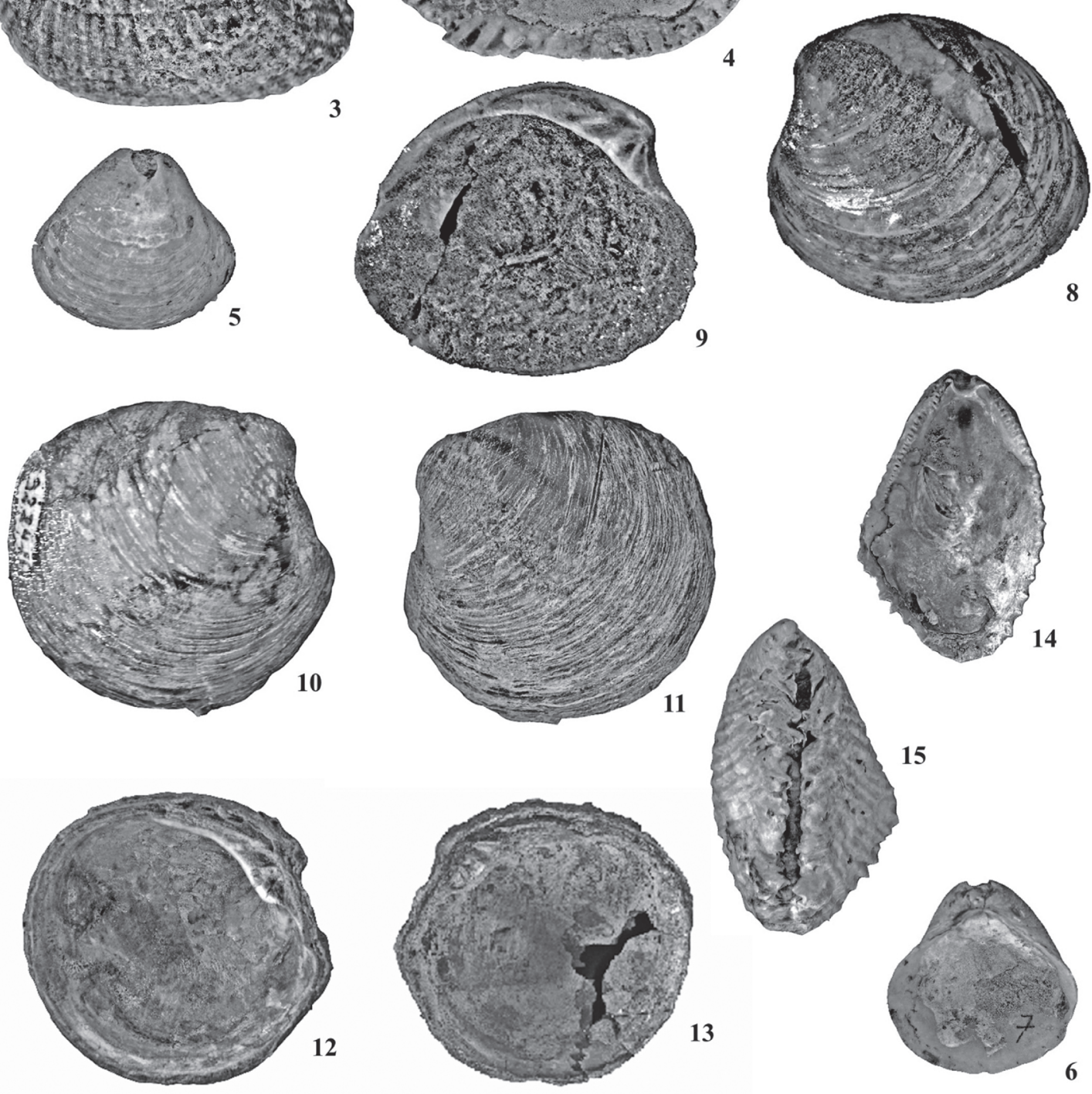


\section{LÁMINA 2}

Figuras 1-6: Zygochlamys rizzoloi sp. nov.

1-2: Valva izquierda; vistas exterior e interior de paratipo (x 1). MACN- Pi 4795.

3-4: Valva derecha; vistas exterior e interior de holotipo (x 1). MACN-Pi 4794.

5: $\quad$ Detalle de aurícula anterior de valva izquierda (x 3). MACN-Pi 4795.

6: $\quad$ Detalle de aurícula posterior de valva derecha (x 3). MACN-Pi 4794.

Figuras 7-12: Amusium rorii sp. nov.

7-8: Vistas exterior e interior de valva derecha (x 1). Holotipo, MACN-Pi 4791.

9: $\quad$ Detalle de aurícula anterior derecha, vista exterior (x 1). Paratipo, MACN-Pi 4792.

10: Detalle de ornamentación interna en valva izquierda (x 1). MACN-Pi 4793.

11: Detalle de ornamentación interna en valva derecha (x 1). MACN-Pi 4792.

12: Vista parcial interna de paratipo (x 1). MACN-Pi 4792. 

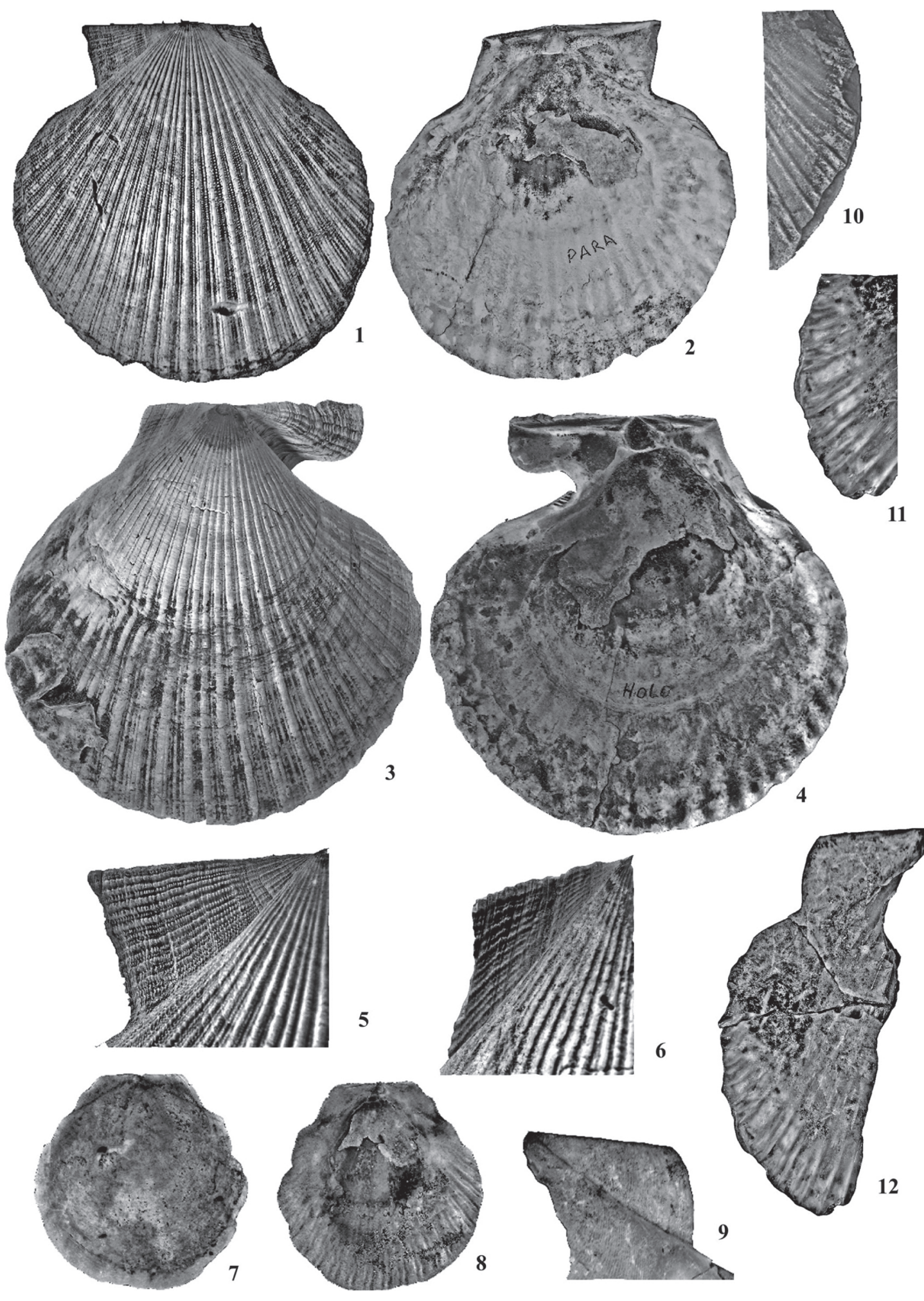

$\oplus$

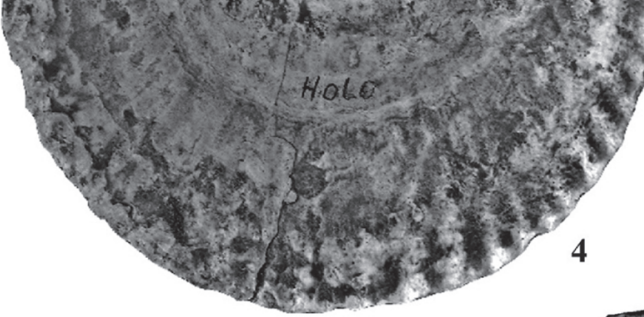

๑)
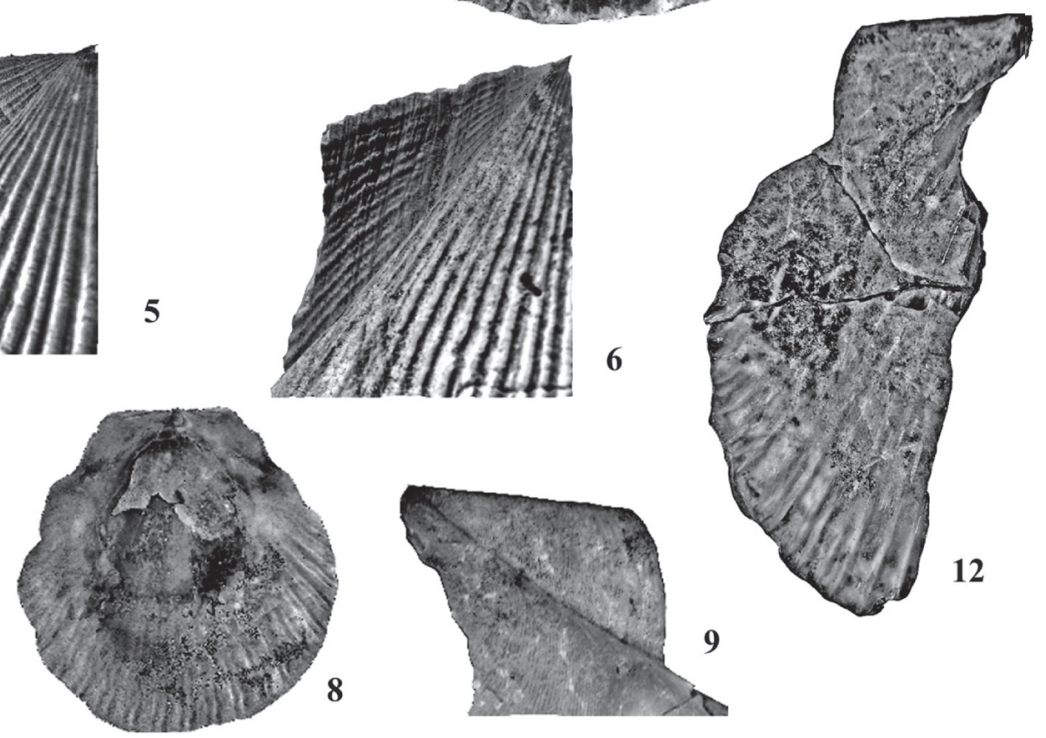


\section{LÁMINA 3}

Figuras 1-3: Sconsia magdai sp. nov.

1: $\quad$ Vista ventral (x 1). Holotipo, MPB 3201-26.

2-3: Vistas dorsal y apical (x 1). Paratipo, MPB 3202-26.

Figuras 4-6: Torcula magna sp. nov.

4: $\quad$ Vista ventral (x 1). Paratipo, MPB 3212-26.

5: $\quad$ Vista ventral (x 1). MPB 3214-26.

6: $\quad$ Detalle de ornamentación espiral (x 1,25). Holotipo MACN-Pi 4851.

Figuras 7-11: Eudolium lissiei sp. nov.

7-8: Vistas dorsal y ventral (x 1). Holotipo, MPB 3952-26.

9-11: Vistas apical, ventral y dorsal (x1). Paratipo, MACN-Pi 4816.

Figuras 12-14: Mitra (Fusimitra) carlosi sp. nov. Holotipo, MACN-Pi 4824.

12: $\quad$ Detalle de abertura (x 2).

13-14: Vistas dorsal y ventral (x 1). 

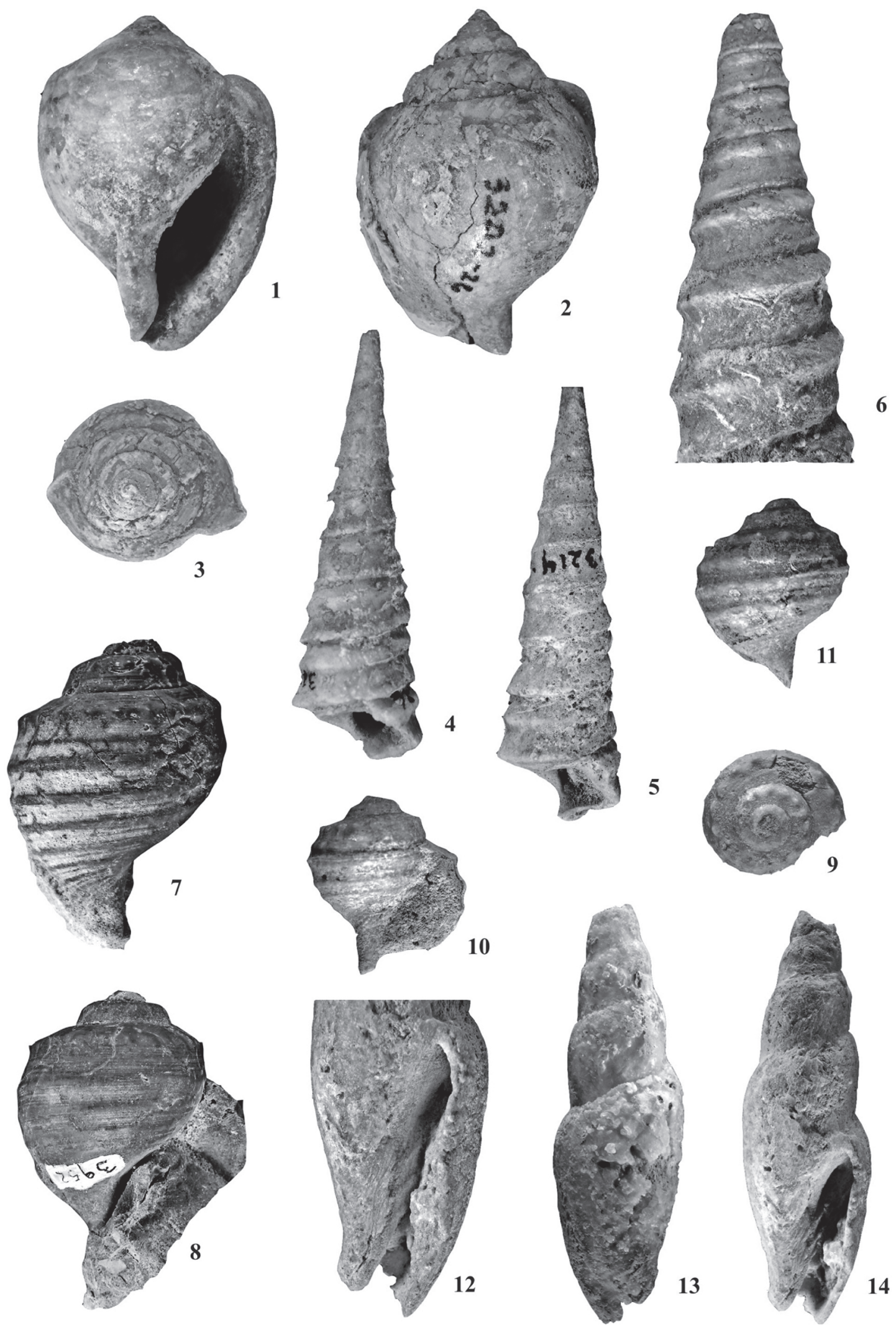

$\oplus$ 


\section{LÁMINA 4}

Figuras 1-4: $\quad$ Penion patagonensis sp. nov. Holotipo MACN-Pi 4834.

1-2: Vistas ventral y dorsal (x 1).

3: $\quad$ Detalle de abertura $(\mathrm{x} 1,50)$.

4: $\quad$ Vista apical (x 1).

Figuras 5-7: $\quad$ Magnatica hansi sp. nov.

5: $\quad$ Vista ventral (x 1). Holotipo, MACN-Pi 4812.

6: Vista dorsal (x 1). Paratipo, MACN-Pi 4813.

7: $\quad$ Detalle de labio interno (x 2,50). MACN-Pi 4812.

Figuras 8-9: 'Spirocolpus' adapicis sp. nov.

8: $\quad$ Vista ventral (x 3). Holotipo, MACN-Pi 4806.

9: $\quad$ Detalles de abertura y seno apertural (x 3). Paratipo, MACN-Pi 4807.

Figuras 10-12: Austroimbricaria brugnii sp. nov. Holotipo, MACN-Pi 4832.

10-11: Vistas dorsal y ventral (x 1,50).

12: Detalle de pliegues columelares (x 2,5).

Figuras 13-15: Chicoreus (Chicoreus) guadalupei sp. nov. Holotipo. MACN-Pi 4820.

13-14: Vistas ventral y dorsal (x 1).

15: Vista apical (x 1).

Figuras 16-17: Polystira cingula sp. nov.

16: Vista ventral (x 1). Holotipo, MACN-Pi 4837.

17: Vista dorsal (x 1). Paratipo, MACN-Pi 4838. 

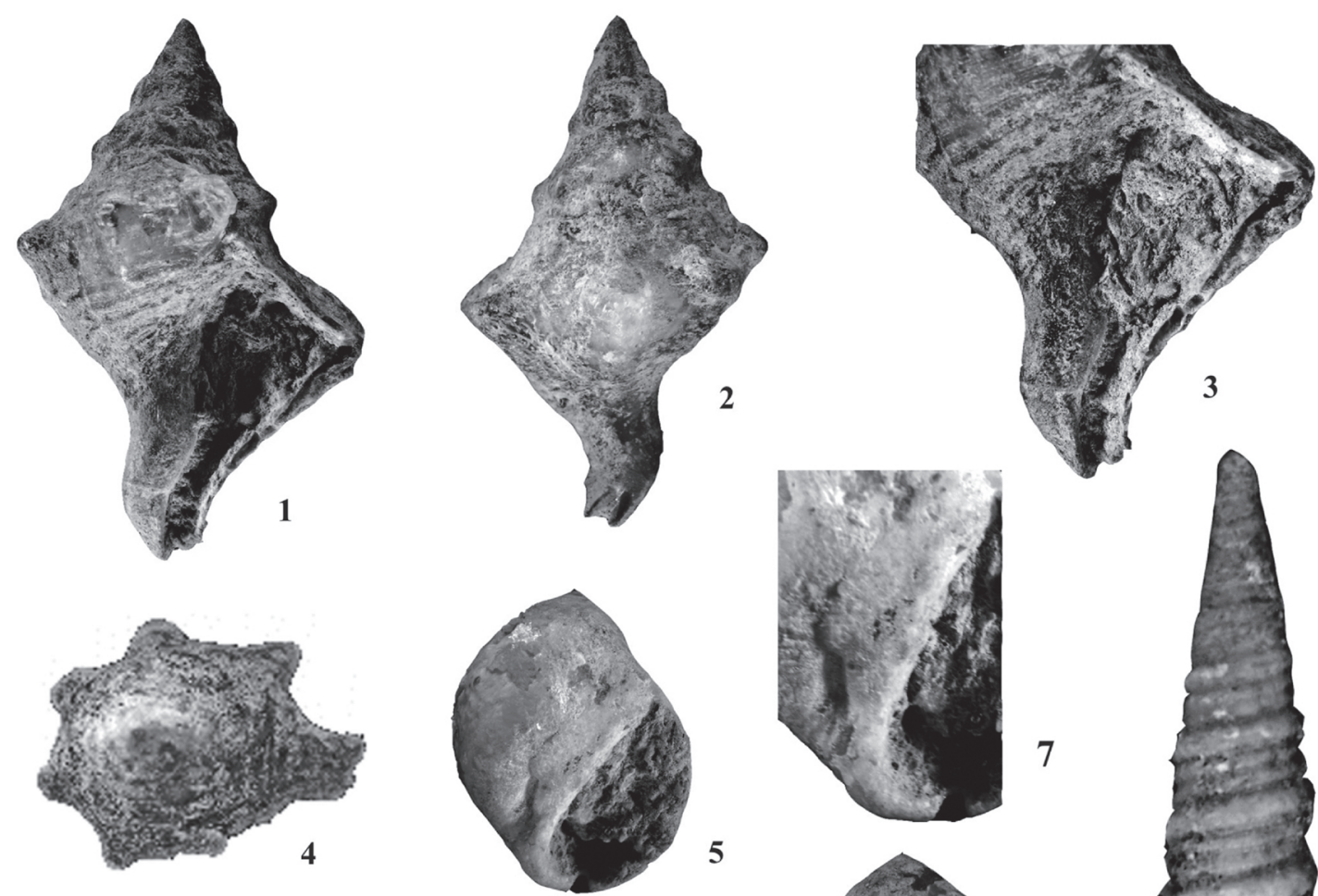

$\oplus$
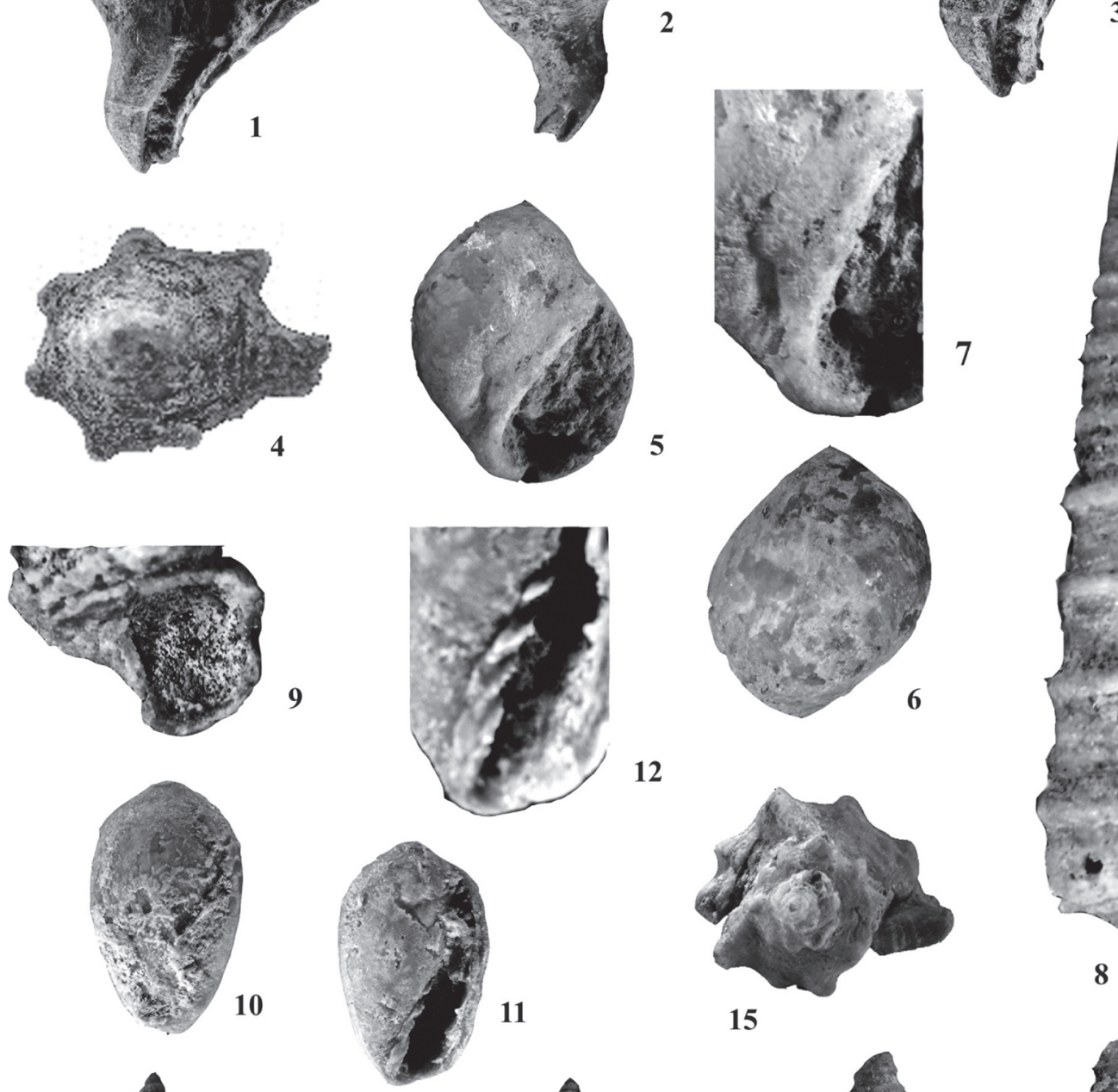

12

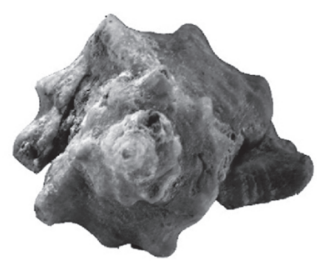

15
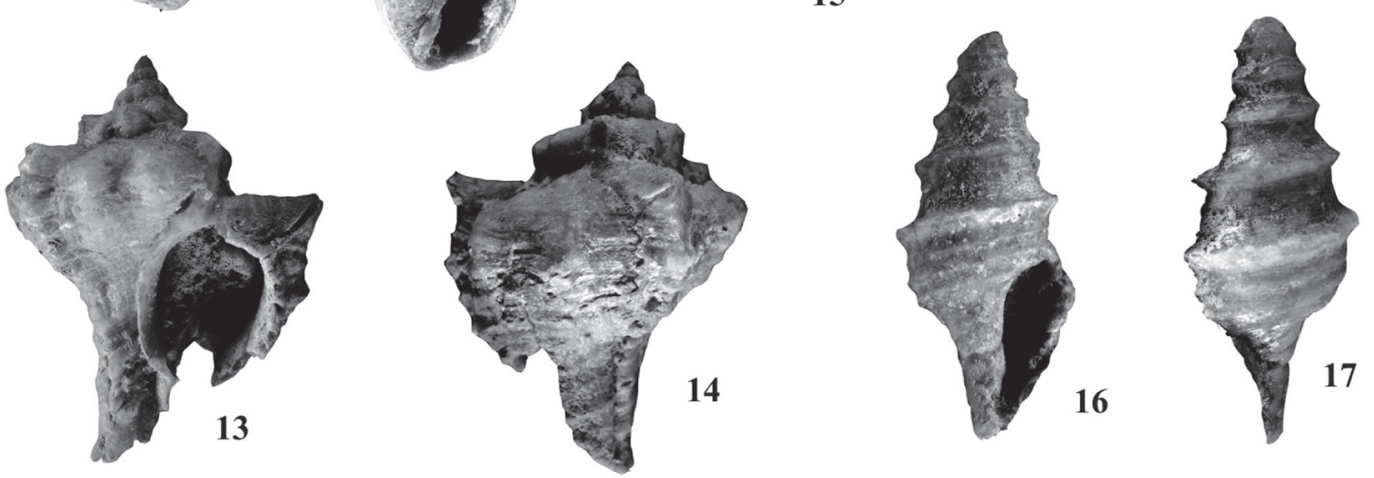

$\oplus$ 